\title{
Photolysis frequency measurement techniques: results of a comparison within the ACCENT project
}

\author{
B. Bohn ${ }^{1}$, G. K. Corlett ${ }^{2}$, M. Gillmann ${ }^{3, *}$, S. Sanghavi ${ }^{3}$, G. Stange ${ }^{4}$, E. Tensing ${ }^{4}$, M. Vrekoussis ${ }^{5, * *}$, W. J. Bloss ${ }^{6, * * *}$, \\ L. J. Clapp ${ }^{7}$, M. Kortner ${ }^{8, * * * *}$, H.-P. Dorn ${ }^{1}$, P. S. Monks ${ }^{2}$, U. Platt ${ }^{3}$, C. Plass-Dülmer ${ }^{4}$, N. Mihalopoulos ${ }^{5}$, D. E. Heard ${ }^{6}$, \\ K. C. Clemitshaw ${ }^{7, * * * * *}$, F. X. Meixner ${ }^{8}$, A. S. H. Prevot ${ }^{9}$, and R. Schmitt ${ }^{10}$ \\ ${ }^{1}$ Institut für Chemie und Dynamik der Geosphäre 2: Troposphäre, Forschungszentrum Jülich, 52425 Jülich, Germany \\ ${ }^{2}$ Department of Chemistry, University of Leicester, Leicester LE1 7RH, UK \\ ${ }^{3}$ Institut für Umweltphysik, Universität Heidelberg, 69120 Heidelberg, Germany \\ ${ }^{4}$ Deutscher Wetterdienst, Meteorologisches Observatorium Hohenpeissenberg, 82383 Hohenpeissenberg, Germany \\ ${ }^{5}$ Environmental Chemistry Laboratory, University of Crete, 71003 Voutes, Heraklion, Greece \\ ${ }^{6}$ School of Chemistry, University of Leeds, Leeds LS2 9JT, UK \\ ${ }^{7}$ Department of Environmental Science and Technology, Imperial College London, Silwood Park Campus, \\ Ascot SL5 7PY, UK \\ ${ }^{8}$ Biogeochemistry Department, Max Planck Institute for Chemistry, 55128 Mainz, Germany \\ ${ }^{9}$ Laboratory of Atmospheric Chemistry, Paul Scherrer Institute, 5232 Villigen, Switzerland \\ ${ }^{10}$ Meteorologie Consult GmbH (Metcon), 61462 Königstein, Germany \\ * now at: SIG Plasmax GmbH, 22145 Hamburg, Germany \\ ** now at: Institut für Umweltphysik, University of Bremen, 28359 Bremen, Germany \\ *** now at: School of Geography, Earth \& Environmental Sciences, University of Birmingham, \\ Birmingham B15 2TT, UK \\ **** now at: Müller-BBM GmbH, 63589 Linsengericht, Germany \\ ****** now at: Department of Earth Sciences, Royal Holloway, University of London, Egham TW20 0EX, UK
}

Received: 7 April 2008 - Published in Atmos. Chem. Phys. Discuss.: 2 June 2008

Revised: 19 August 2008 - Accepted: 19 August 2008 - Published: 10 September 2008

\begin{abstract}
An intercomparison of different radiometric techniques measuring atmospheric photolysis frequencies $j\left(\mathrm{NO}_{2}\right), j(\mathrm{HCHO})$ and $j\left(\mathrm{O}^{1} \mathrm{D}\right)$ was carried out in a twoweek field campaign in June 2005 at Jülich, Germany. Three double-monochromator based spectroradiometers (DM-SR), three single-monochromator based spectroradiometers with diode-array detectors (SM-SR) and seventeen filter radiometers (FR) (ten $j\left(\mathrm{NO}_{2}\right)$-FR, seven $j\left(\mathrm{O}^{1} \mathrm{D}\right)$-FR) took part in this comparison. For $j\left(\mathrm{NO}_{2}\right)$, all spectroradiometer results agreed within $\pm 3 \%$. For $j(\mathrm{HCHO})$, agreement was slightly poorer between $-8 \%$ and $+4 \%$ of the DM-SR reference result. For the SM-SR deviations were explained by poorer spectral resolutions and lower accuracies caused by decreased sensitivities of the photodiode arrays in a wavelength range below $350 \mathrm{~nm}$. For $j\left(\mathrm{O}^{1} \mathrm{D}\right)$, the results were
\end{abstract}

Correspondence to: B. Bohn

(b.bohn@fz-juelich.de) more complex within $+8 \%$ and $-4 \%$ with increasing deviations towards larger solar zenith angles for the SM-SR. The direction and the magnitude of the deviations were dependent on the technique of background determination. All $j\left(\mathrm{NO}_{2}\right)$-FR showed good linearity with single calibration factors being sufficient to convert from output voltages to $j\left(\mathrm{NO}_{2}\right)$. Measurements were feasible until sunset and comparison with previous calibrations showed good long-term stability. For the $j\left(\mathrm{O}^{1} \mathrm{D}\right)$-FR, conversion from output voltages to $j\left(\mathrm{O}^{1} \mathrm{D}\right)$ needed calibration factors and correction functions considering the influences of total ozone column and elevation of the sun. All instruments showed good linearity at photolysis frequencies exceeding about $10 \%$ of maximum values. At larger solar zenith angles, the agreement was non-uniform with deviations explainable by insufficient correction functions. Comparison with previous calibrations for some $j\left(\mathrm{O}^{1} \mathrm{D}\right)$-FR indicated drifts of calibration factors.

Published by Copernicus Publications on behalf of the European Geosciences Union. 


\section{Introduction}

ACCENT (Atmospheric Composition Change - The European Network of Excellence) is a European joint research programme (http://www.accent-network.org/). An integration task within this project is the quality assurance of measurement techniques used in field campaigns. The current work is part of this activity and concerned radiometric measurements of atmospheric photolysis frequencies.

Atmospheric chemistry is controlled by the formation of highly reactive radical species in photolysis processes. These radicals initiate complex chain reactions, e.g. the degradation of many trace gases released into the atmosphere by anthropogenic, biogenic and geological processes (e.g. Ehhalt, 1999; Jenkin and Clemitshaw, 2000). Photolysis frequencies are first-order rate constants quantifying the rate of photolysis processes, i.e. of primary radical production. It is therefore important to perform reliable measurements of photolysis frequencies with accurate techniques, in order to improve our current knowledge concerning the atmospheric photochemistry.

A summary of available techniques of photolysis frequency measurements in the atmosphere was given in recent reviews by Clemitshaw (2004) and Hofzumahaus (2006). Although there are absolute chemical methods available (chemical actinometry), radiometric measurement techniques are most common for reasons of convenience and versatility. The radiometric approach of photolysis frequency determinations is based on measurements of solar actinic radiation either spectrally resolved with spectroradiometers or integrated over selected wavelength ranges with filter radiometers. The relationship for a photolysis reaction

$\mathrm{A}+h v \rightarrow \mathrm{B}(+$ products $)$

is given by the following equation:

$j(\mathrm{~A} \rightarrow \mathrm{B})=\int_{\lambda} F_{\lambda} \sigma_{\mathrm{A}} \phi_{\mathrm{B}} \mathrm{d} \lambda$.

The notation $j(\mathrm{~A} \rightarrow \mathrm{B})$ is often abbreviated $j(\mathrm{~A})$ or $j(\mathrm{~B})$ dependent on context. $j\left(\mathrm{NO}_{2}\right)$ and $j\left(\mathrm{O}^{1} \mathrm{D}\right)$ are well known examples for these abbreviations (see Eqs. 3 and 5 below). $F_{\lambda}$ is the spectral actinic photon flux density (denoted spectral actinic flux in the following), $\sigma_{\mathrm{A}}$ is the absorption cross section of the reactant molecule $\mathrm{A}$, and $\phi_{\mathrm{B}}$ is the quantum yield of the photo-product $\mathrm{B}$. These quantities are dependent on wavelength $\lambda$ and consequently the integrations in Eq. (2) are covering wavelength ranges where the product $F_{\lambda} \sigma_{\mathrm{A}} \phi_{\mathrm{B}} \neq 0$. In the troposphere photolysis processes mainly proceed in the wavelength range $290 \mathrm{~nm} \leq \lambda \leq 420 \mathrm{~nm}$. Important exceptions are the photolysis of $\mathrm{NO}_{3}(420-640 \mathrm{~nm})$ and the photolysis of $\mathrm{O}_{3}$ in the Chappius band (440-850 nm).

For major atmospheric photolysis processes the molecular parameters $\sigma_{\mathrm{A}}$ and $\phi_{\mathrm{B}}$ are known from laboratory work. Significant uncertainties still exist for less abundant compounds, e.g. for many complex carbonyl compounds formed as intermediates in atmospheric VOC degradations. The accuracy of photolysis frequency measurements based on Eq. (2) depends on both accurate spectral actinic flux and molecular parameters. However, the uncertainties of the molecular parameters are not the scope of the present work. Previous field measurement studies combining chemical actinometry and spectroradiometry have pointed to errors in molecular parameters (e.g. Müller et al., 1995; Shetter et al., 1996) but they can only be quantified through laboratory studies. The question addressed in this work was if different instruments and measurement techniques produce consistent photolysis frequency results based on common sets of molecular parameters.

Technically, the radiometric measurement of actinic flux requires receiver optics reproducing the geometric reception characteristics of molecules in the gas-phase, namely an angle-independent sensitivity over a $2 \pi$ sr (or $4 \pi$ sr) solid angle field of view (Hofzumahaus, 2006). This can be achieved by frosted quartz or teflon domes combined with horizontal shadow rings limiting the field of view to one hemisphere. The collected radiation is then guided towards dispersive elements dependent on technique as described briefly in the following.

Spectroradiometers (SR) measure $F_{\lambda}$ as a function of wavelength. Spectral resolutions of $\approx 1 \mathrm{~nm}$ are generally sufficient for measurements aiming at photolysis frequencies. However, this is not a strict rule and depends on the wavelength range, the photolysis process and the desired accuracy (Hofzumahaus et al., 1999). Spectroradiometry is the most versatile approach because any photolysis frequency can be calculated from the $F_{\lambda}$ spectra if $\sigma_{\mathrm{A}}$ and $\phi_{\mathrm{B}}$ in Eq. (2) are known. There are two principal methods of spectroradiometry utilised for atmospheric measurements. The first method uses double monochromators for wavelength separation and successive measurements with single detectors (e.g. photomultipliers) upon scanning the wavelength. This concept will be denoted DM-SR in the following and is excellent for stray light suppression which is important in the UV-B range (e.g. Shetter and Müller, 1999; Hofzumahaus et al., 1999). Drawbacks are the comparatively long time periods to complete the wavelength scans $(\geq 30 \mathrm{~s})$ and the use of motor-driven optical components which may cause stability problems under field measurement conditions. The second method uses single monochromators and detector arrays (e.g. photodiode arrays) for simultaneous measurements covering the whole range of relevant wavelengths. This concept will be denoted SM-SR in the following and has the advantage of high time-resolution and stability because no movable parts are involved. These are important requirements for example for aircraft measurements (e.g. Jäckel et al., 2005; Stark et al., 2007). Drawbacks are insufficient stray-light suppression and cross-talk within the detector arrays limiting accuracy in the UV-B (e.g. Kanaya et al., 2003; Edwards and Monks, 2003; Jäckel et al., 2006). With both types of 
Table 1. Overview of contributing institutions, acronyms, and instruments: Double-monochromator spectroradiometers (DM-SR), singlemonochromator spectroradiometers (SM-SR) and different types of filter radiometers (FR). Plus signs (+) indicate a further, similar instrument.

\begin{tabular}{|c|c|c|c|c|c|}
\hline Institution & & DM-SR & SM-SR & $j\left(\mathrm{NO}_{2}\right)-\mathrm{FR}$ & $j\left(\mathrm{O}^{1} \mathrm{D}\right)-\mathrm{FR}$ \\
\hline Forschungszentrum Jülich & FZJ & FZJ-SR1 + SR2 & FZJ-SR3 & $\mathrm{FZJ}-\mathrm{FR} 1^{\mathrm{a}}+\mathrm{FR} 2^{\mathrm{a}}$ & FZJ-FR3 + FR4 \\
\hline Deutscher Wetterdienst & DWD & - & DWD-SR & DWD-FR1 ${ }^{\mathrm{a}}$ & DWD-FR2 + FR3 \\
\hline University of Leicester & ULI & - & ULI-SR & ULI-FR1 & ULI-FR2 \\
\hline University of Crete & UCR & - & - & UCR-FR1 & UCR-FR2 \\
\hline Max Planck Institute for Chemistry & MPIC & - & - & MPIC-FR1 + FR2 & - \\
\hline University of Heidelberg & IUP & IUP-SR & - & - & - \\
\hline University of Leeds & ULE & - & - & - & ULE-FR \\
\hline Imperial College London & ICL & - & - & ICL-FR ${ }^{\mathrm{a}}$ & - \\
\hline Paul Scherrer Institute & PSI & - & - & PSI-FR ${ }^{a}$ & - \\
\hline Metcon $\mathrm{GmbH}$ & MET & - & - & MET-FR & - \\
\hline
\end{tabular}

a $4 \pi$ sr instruments with two opposite $2 \pi$ sr receiver optics

spectroradiometers $F_{\lambda}$ measurements can be made on an absolute scale because calibrations are feasible with irradiance standards that can be traced to national standards. However, in this procedure the properties of the actinic receiver optics must be taken into account (Hofzumahaus et al., 1999). Moreover, actinic flux under atmospheric conditions can be greater by two orders of magnitude compared with typical calibration conditions in the laboratory, i.e. there are high demands on linearity and dynamic range.

Filter radiometers (FR) use combinations of optical filters and detectors instead of monochromators to measure $F_{\lambda}$ integrated over expanded wavelength ranges. The relative spectral sensitivities are chosen to closely match those of the products $\sigma_{\mathrm{A}} \phi_{\mathrm{B}}$ in Eq. (2) for a selected photolysis reaction. Ideally, the FR outputs are then proportional to the corresponding photolysis frequencies and absolute calibrations can be obtained from in-field comparisons with reference instruments, e.g. spectroradiometers.

From the point of view of atmospheric chemistry, nitrogen dioxide photolysis and ozone photolysis in the Huggins bands are of particular importance because they form prominent species in secondary reactions, namely ozone:

$$
\begin{array}{r}
\mathrm{NO}_{2}+h v(\lambda \leq 420 \mathrm{~nm}) \longrightarrow \mathrm{O}\left({ }^{3} \mathrm{P}\right)+\mathrm{NO} \\
\mathrm{O}\left({ }^{3} \mathrm{P}\right)+\mathrm{O}_{2}+\mathrm{M} \longrightarrow \mathrm{O}_{3}+\mathrm{M}
\end{array}
$$

and $\mathrm{OH}$ radicals:

$$
\begin{array}{r}
\mathrm{O}_{3}+h v(\lambda \leq 340 \mathrm{~nm}) \longrightarrow \mathrm{O}\left({ }^{1} \mathrm{D}\right)+\mathrm{O}_{2} \\
\mathrm{O}\left({ }^{1} \mathrm{D}\right)+\mathrm{H}_{2} \mathrm{O} \longrightarrow 2 \mathrm{OH}
\end{array}
$$

Consequently, filter radiometers were designed to specifically measure the photolysis frequencies $j\left(\mathrm{NO}_{2}\right)$ (Reaction 3) or $j\left(\mathrm{O}^{1} \mathrm{D}\right)$ (Reaction 5) (Junkermann et al., 1989; Volz-Thomas et al., 1996). The main advantage of filter radiometers is that the instruments are light-weight and easy to handle making them ideal for routine measurements with high time resolution $(1 \mathrm{~s})$. The disadvantage of filter radiometers is that only photolysis frequencies of a single reaction are obtained with limited potential to deduce other photolysis frequencies.

The purpose of this work was to bring together various types of instruments from European groups for an in-field comparison of photolysis frequency measurements. There were several objectives. Firstly, to compare independently calibrated spectroradiometers under atmospheric conditions. Secondly, to assess the performance of SM-SR in particular for measurements in the UV-B, i.e. for $j\left(\mathrm{O}^{1} \mathrm{D}\right)$, by comparison with a DM-SR reference. Thirdly, to provide a common spectroradiometer reference for the calibration of filter radiometers.

Besides $j\left(\mathrm{O}^{1} \mathrm{D}\right)$ and $j\left(\mathrm{NO}_{2}\right)$ in this work we will examine the atmospherically important photolysis frequencies $j(\mathrm{HCHO})_{\mathrm{m}}$ and $j(\mathrm{HCHO})_{\mathrm{r}}$ of methanal (formaldehyde) photolysis:

$$
\begin{aligned}
& \mathrm{HCHO}+h v(\lambda \leq 355 \mathrm{~nm}) \longrightarrow \mathrm{H}_{2}+\mathrm{CO} \\
& \mathrm{HCHO}+h v(\lambda \leq 335 \mathrm{~nm}) \longrightarrow \mathrm{H}+\mathrm{HCO}
\end{aligned}
$$

The indices $m$ and $r$ stand for the molecular (Reaction 7) and the radical channel (Reaction 8), respectively. (Reaction 7) is the main source of atmospheric $\mathrm{H}_{2}$ while (Reaction 8) is an important primary source of $\mathrm{HO}_{\mathrm{x}}$ because both radical fragments quantitatively form $\mathrm{HO}_{2}$ under tropospheric conditions. Spectrally HCHO photolysis falls between those of $\mathrm{O}_{3}$ and $\mathrm{NO}_{2}$. Nevertheless, the measurement of $\mathrm{HCHO}$ photolysis frequencies with spectroradiometers is difficult because the $\mathrm{HCHO}$ absorption spectrum is composed of sharp peaks requiring measurements with sufficient spectral resolutions. Other photolysis frequencies will not be addressed specifically but this does not imply they are unimportant. 

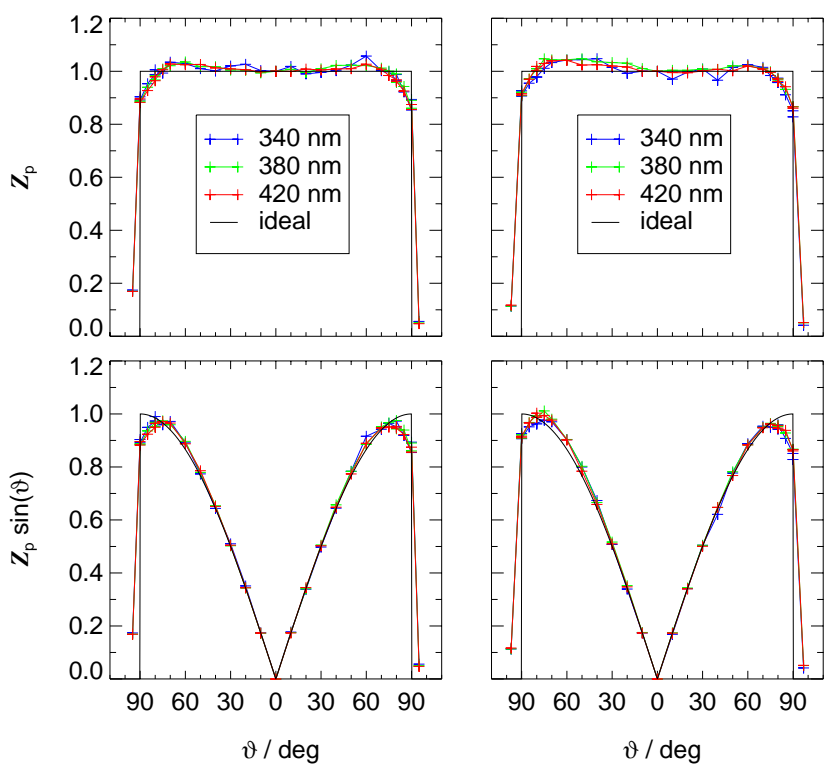

Fig. 1. Upper panels: Relative response $Z_{\mathrm{p}}$ of the reference instrument receiver optics as a function of polar angle and wavelength. The two plots show the dependencies for two perpendicular orientations with respect to azimuth angles. Lower panels: $Z_{\mathrm{p}}$ from the upper panels multiplied by $\sin (\vartheta)$ indicating the relative weight for an isotropic sky radiance distribution of the upper hemisphere.

\section{Experimental}

Table 1 gives an overview of participating groups and instruments. Most groups operated one filter radiometer (University of Leeds (ULE), Imperial College London (ICL), Paul Scherrer Institute (PSI) and Metcon GmbH (MET)), two similar filter radiometers (Max Planck Institute for Chemistry (MPIC)) or a pair of different filter radiometers (University of Crete (UCR)). Moreover, except for MET these groups had no independent means of calibration with a reference instrument. University of Heidelberg (IUP) operated a DMSR. Deutscher Wetterdienst (DWD) and University of Leicester (ULI) operated both SM-SR and pairs of different FR. These two groups had their own irradiance standards which were used for independent calibrations. Forschungszentrum Jülich (FZJ) provided the DM-SR reference and also operated SM-SR and pairs of different FR. In the following subsections the different instrument types will be briefly introduced and technical aspects of the intercomparison will be addressed. The reference instrument will be described in more detail than the others.

\subsection{DM-SR and reference instrument}

A DM-SR by FZJ was selected as a reference (FZJSR1). The instrument was assembled from a doublemonochromator (Bentham, DTM 300), a $10 \mathrm{~m}$ quartz fibre, a $30 \mathrm{~mm}$ diameter quartz receiver (Metcon $\mathrm{GmbH}$ ), and a
$350 \mathrm{~mm}$ diameter horizontal shadow ring. Radiation was detected with a UV sensitive photomultiplier (EMI, 9250QB). The setup was described in detail by Hofzumahaus et al. (1999). Here we give additional or updated information on this instrument to justify its use as a reference.

Spectral sensitivity calibration was made with a PTB traceable $1000 \mathrm{~W}$ irradiance standard (Gigahertz-Optik, BN9101). $45 \mathrm{~W}$ secondary standards (Optronic) were used to check the stability of the instrument during the campaign which remained stable to $2 \%$, independent of wavelength. Wavelength offsets at positions (air) $296.728 \mathrm{~nm}$, $334.148 \mathrm{~nm}$ and $407.784 \mathrm{~nm}$ were checked regularly using a low-pressure mercury lamp (Oriel, 6035). In five of these checks between 25 May and 14 June 2005 minimum and maximum offsets of $-0.02 \mathrm{~nm}$ and $+0.03 \mathrm{~nm}$ were found. For a given wavelength these offsets were stable within $\pm 0.02 \mathrm{~nm}$. This stability was achieved by temperaturestabilising the double-monochromator to about $\pm 1 \mathrm{~K}$. Wavelengths steps and spectral resolution (FWHM, full width at half maximum) were set to $1 \mathrm{~nm}$. A scanning range 280 $420 \mathrm{~nm}$ was selected resulting in typical scanning times of about $90 \mathrm{~s}$. Total measurement times for spectra including background determinations were about $110 \mathrm{~s}$.

The angular response properties of the optical receiver of FZJ-SR1 were tested in the laboratory as described by Hofzumahaus et al. (1999). Generally, these properties were different for each optical receiver and optimised by thorough alignments of internal parts. The upper panels of Fig. 1 show the relative response $Z_{\mathrm{p}}$ as a function of polar angle $(\vartheta)$ for three wavelengths within the scanning range. In the lower panels of the same figure these data were multiplied by $\sin (\vartheta)$ to demonstrate the effects of the $Z_{\mathrm{p}}$ functions on actinic flux reception assuming a hypothetical isotropic sky radiance distribution. For comparison the black lines in both panels illustrate the ideal behaviour.

The lower panels of Fig. 1 can be rationalised by the relation between spectral actinic flux and spectral radiance $\left(L_{\lambda}\right)$ :

$$
F_{\lambda}(\lambda)=\int_{0}^{2 \pi} \int_{0}^{\pi} L_{\lambda}(\lambda, \vartheta, \varphi) \sin (\vartheta) \mathrm{d} \vartheta \mathrm{d} \varphi
$$

Assuming an isotropic radiance distribution ( $L_{\lambda}=$ constant), the measured spectral actinic flux is proportional to the integrals underneath the curves in the lower panels of Fig. 1. This demonstrates that for diffuse radiation the receiver characteristics at large polar angles are very important also considering unintentional reception of up-welling radiation.

Under conditions with low ground albedo up-welling radiation can be neglected and the ratios $Z_{\mathrm{H}}$ of the integrals (measured/ideal) under the $Z_{\mathrm{p}} \sin (\vartheta)$ curves in a range $\vartheta \leq 90^{\circ}$ can be used to quantify the deviation caused by the non-ideal angular response characteristics (Hofzumahaus et al., 1999). Figure 2 shows the corresponding correction factors $1 / Z_{\mathrm{H}}$ as functions of wavelength. These factors are 
close to unity and independent of wavelength in a range below $450 \mathrm{~nm}$ and therefore no correction was applied. Of course, under atmospheric conditions diffuse sky radiation is not isotropic and the contribution from direct sun is scaled by the receiver by $Z_{\mathrm{p}}(\mathrm{SZA})$ (SZA=solar zenith angle). Nevertheless, the deviations were estimated to remain within $2 \%$ under typical conditions during the current campaign. $\mathrm{Nu}-$ merical tests showed that the correction factors exhibited little dependence on the angular radiance distribution. Moreover, the contribution of direct sun generally diminishes with decreasing solar elevation when $Z_{\mathrm{p}}(\mathrm{SZA})$ drops significantly in a range $\mathrm{SZA}>80^{\circ}$.

It should be noted that under conditions where up-welling radiation is not negligible the situation is more complex. In particular $4 \pi$ sr aircraft applications with two optical receivers covering opposite hemispheres need extended considerations for two reasons. Firstly, SZA and polar angles may differ during flight manoeuvres unless technical equipment ensures compensating movements of the receivers (Jäckel et al., 2005). Secondly, measures to minimise cross talks to the opposite hemispheres are complicated by restrictions to the size of horizontal shadow rings for aerodynamic reasons. In principle the receivers should be selected and adjusted to obtain optimum $4 \pi \mathrm{sr}$ response. However, this implies that up- and down-welling radiation may not be accurately separable. Examples for aircraft applications of actinic flux receiver optics can be found elsewhere (e.g. VolzThomas et al., 1996; Hofzumahaus et al., 2002; Shetter et al., 2003; Jäckel et al., 2005).

Total accuracy of the spectral actinic flux measurements of the reference instrument was estimated 5-7\% based on the accuracy of the irradiance standard, the calibration procedure and the uncertainties regarding the angular response properties of the optical receiver. FZJ-SR1 participated in two previous international intercomparison campaigns for spectral actinic flux measurements, namely IPMMI (Bais et al., 2003) and INSPECTRO (Thiel et al., 2008). In these comparisons agreement within 5-10\% was obtained with other absolutely calibrated spectroradiometers consistent with accuracy estimates.

A second DM-SR of FZJ (FZJ-SR2) was operative which measured with two receiver optics simultaneously. The setup was similar to the reference instrument but the total slit height of the double monochromator was used for two separate optical paths. One channel measured the total spectral actinic flux, the other measured the contribution from diffuse sky radiation by obstructing direct sun with an additional shadow ring. More details on this technique can be found elsewhere (Bohn and Zilken, 2005). In the present work the measurement of diffuse sky radiation merely served as a charaterisation of ambient conditions regarding the presence and contribution of direct sun. The calibration procedure, scanning scheme and wavelength stability were similar to the reference instrument. Angular response characteristics were close to those shown in Fig. 1. A slightly poorer per-
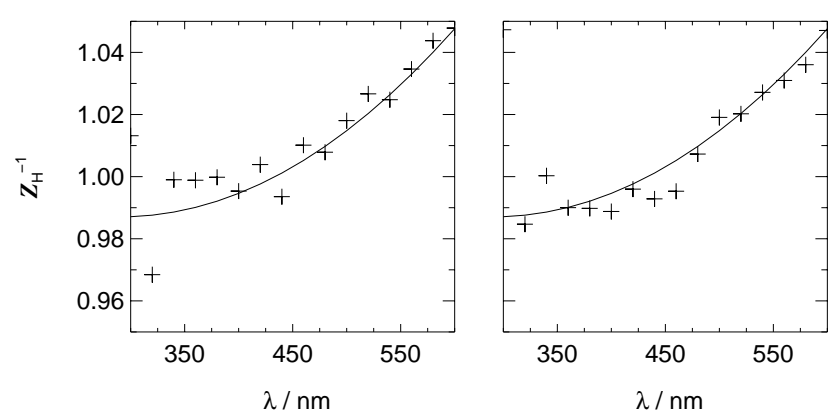

Fig. 2. Correction factors $1 / Z_{\mathrm{H}}$ for isotropic sky radiation from the upper hemisphere as a function of wavelength. Left and right panels correspond to left and right panels in Fig. 1, respectively. Variations at short wavelengths were caused by low signals from laboratory lamps. The full lines show a fitted mean dependence considering all measured data.

formance towards large polar angles was compensated by a correction factor $1 / Z_{\mathrm{H}}=1.03$ for the receiver measuring the total actinic flux. Because of co-channel operation measurement times of FZJ-SR 2 were increased to about $135 \mathrm{~s}$ per spectrum.

The DM-SR of University of Heidelberg (IUP-SR) was assembled from a double-monochromator (Bentham, DMc 150), a $3 \mathrm{~m}$ quartz fibre, a hemispherical PTFE (teflon) receiver (10 mm diameter), and a $100 \mathrm{~mm}$ diameter horizontal shadow ring. Radiation detection was made by a cooled ( $263 \mathrm{~K}$ ) photomultiplier tube (Bentham, DH-10-Te). A scanning range $250-600 \mathrm{~nm}$ and a FWHM of $1 \mathrm{~nm}$ was used. Wavelength steps were $5 \mathrm{~nm}$ in the range $250-280 \mathrm{~nm}$ (background measurement), $1 \mathrm{~nm}$ in the range $280-450 \mathrm{~nm}$ and $5 \mathrm{~nm}$ in the range $450-600 \mathrm{~nm}$. This scheme resulted in scanning times of about $6 \mathrm{~min}$. Wavelength calibration was performed with a low pressure mercury lamp and wavelength offsets were considered in the data analysis. Spectral sensitivity calibration was made directly after the intercomparison with the same irradiance standard as used for the reference instrument. As for the other SR described above, an accuracy of 5\% was estimated for this calibration. However, the angular response properties of the teflon receiver optics of IUP-SR were found to be unsuitable with sensitivities decreasing significantly towards larger polar angles. As a first approximation this was compensated by a correction factor $1 / Z_{\mathrm{H}}=1.52$ in the data analysis again obtained assuming an isotropic angular distribution of sky radiance. The additional uncertainty associated with this correction was estimated 0 $20 \%$ dependent on conditions, i.e. presence or absence of direct sun, SZA and wavelength range.

A further, more general problem of teflon receivers should be mentioned here. A phase transition of the PTFE material at around $292 \mathrm{~K}$ was reported to change the transmittances of teflon diffusers by about 3\% (Ylianttila and Schreder, 2005). This may have affected spectral sensitivities of IUP-SR. Because this potential problem was unnoticed at the time of the 
campaign temperature data were not recorded during measurements and calibrations. We therefore estimate a further $5 \%$ uncertainty for the measurements of IUP-SR. Total uncertainties may thus cumulate to $10-30 \%$, dependent on conditions.

\subsection{SM-SR}

The SM-SR by University of Leicester (ULI-SR) was described in detail by Edwards and Monks (2003) and Monks et al. (2004). Briefly, the instrument was composed of a quartz receiver as described above, a ceramic single monochromator (Zeiss) and a 512-pixel photodiode array (Hamamatsu, S3904). The set-up was developed by Metcon $\mathrm{GmbH}$ and contained in a water-tight aluminium housing for outdoor operation. The ceramic housing of the monochromator ensured excellent wavelength stability with regard to temperature variations specified as $5 \times 10^{-4} \mathrm{~nm} \mathrm{~K}^{-1}$. With a step-size of $0.83 \mathrm{~nm} /$ pixel measurements were feasible between $280 \mathrm{~nm}$ and $700 \mathrm{~nm}$. However, data analysis was confined to a wavelength range $280-450 \mathrm{~nm}$. A $1000 \mathrm{~W}$ NIST traceable irradiance standard (Oriel) was used for calibration under laboratory conditions. The accuracy of the calibration was estimated $8 \%$ in the UV-A and $9 \%$ in the UV-B range, including uncertainties associated with the quartz receiver but not considering any stray-light effects (Edwards and Monks, 2003). Wavelength offsets and slit functions were obtained using $\mathrm{Na}$ and $\mathrm{Hg}$ atomic line lamps. Atmospheric measurements were made with a fixed integration time of $1 \mathrm{~s}$. Spectra were then averaged over 1 min periods. Background signals (electronic and stray-light) were determined in a range 285-290 nm where atmospheric radiation at ground level was negligible. These background signals were subtracted at all wavelengths.

DWD-SR and FZJ-SR3 were similar in construction representing slightly modified versions of the ULI-SR instrument mainly regarding the housings provided by Metcon GmbH. FWHM and wavelength offsets were obtained by measuring emission lines from low pressure mercury lamps. FWHM of DWD-SR was about $2.3 \mathrm{~nm}$ (manufacturer) with wavelength offsets ranging between $0.06 \mathrm{~nm}$ at $297 \mathrm{~nm}$ and $0.01 \mathrm{~nm}$ at $546 \mathrm{~nm}$. The FWHM of FZJ-SR3 was about $1.7 \mathrm{~nm}$ and wavelength offsets ranged between $-0.01 \mathrm{~nm}$ at $297 \mathrm{~nm}$ and $-0.05 \mathrm{~nm}$ at $546 \mathrm{~nm}$. Calibrations were made with the same irradiance standard as for the reference instrument (FZJ) and with a further NIST traceable $1000 \mathrm{~W}$ standard (Optronics Laboratories) (DWD). The calibration procedures were performed in two steps accounting for the low sensitivities of the diode arrays in the UV range and the low outputs of the calibration lamps. Calibration measurements were made at standard $(70 \mathrm{~cm})$ and reduced $(\approx 30 \mathrm{~cm})$ distances between the lamps and the optical receivers. At the shorter distances spectral calibrations were obtained on a relative scale but with improved signal-to-noise ratios. The corresponding relative sensitivities were then transferred to the regular dis- tance by scaling factors from a wavelength range $\geq 400 \mathrm{~nm}$ where good signal-to-noise ratios were obtained at both distances. The accuracy of these calibrations were estimated $5 \%$ above $400 \mathrm{~nm}$ and 6-10\% in the UV range, generally decreasing with decreasing wavelength for DWD-SR and FZJSR3.

Calibrations also included measurements with and without cut-off filters at $320 \mathrm{~nm}$ (Schott, WG320) to quantify the level of stray-light in the range $280-320 \mathrm{~nm}$ and to investigate the cross-talk within the diode arrays. The latter typically led to slightly increasing signals upon approaching the cut-off wavelength of the filters in a range where the transmittance of the filters was negligible. Atmospheric spectra were therefore treated as follows: After subtraction of electronic background obtained in the dark, the derivative of the signal with wavelength was calculated averaging over 3-5 neighbouring pixels. A minimum positive gradient was then defined as significant marking the actual onset of the atmospheric spectrum. At this wavelength the offset was determined and subtracted at all wavelengths. Data from wavelengths below this starting point were neglected.

Up to four different integration times between $0.5 \mathrm{~s}$ and $5 \mathrm{~s}$ were utilised to measure in different spectral ranges, e.g. $1 \mathrm{~s}$ in the UV-A and $5 \mathrm{~s}$ in the UV-B range, dependent on conditions. Final spectra were then assembled to obtain maximum integration times for all wavelengths without saturation. This resulted in typical measurement times of about $12 \mathrm{~s}$ (DWD$\mathrm{SR}$, four integration times) and $8 \mathrm{~s}$ (FZJ-SR3, two integration times) for a single spectrum. These data were saved without further averaging.

\section{$2.3 j\left(\mathrm{NO}_{2}\right)-\mathrm{FR}$ and $j\left(\mathrm{O}^{1} \mathrm{D}\right)-\mathrm{FR}$}

The instrumental setup and properties of $j\left(\mathrm{NO}_{2}\right)$-FR and $j\left(\mathrm{O}^{1} \mathrm{D}\right)$-FR were described in detail by Volz-Thomas et al. (1996) and Junkermann et al. (1989), respectively. Briefly $30 \mathrm{~mm}$ diameter quartz receivers with $140 \mathrm{~mm}$ diameter horizontal shadow rings were used for $2 \pi$ sr radiation collection. For the $j\left(\mathrm{NO}_{2}\right)$-FR, combinations of bandpass and cut-off filters (Schott) were used for the wavelength separation and phototubes (Hamamatsu, R840) for radiation detection. $j\left(\mathrm{O}^{1} \mathrm{D}\right)$-FR used narrow-band interference filters $\left(\lambda_{\max } \approx 300 \mathrm{~nm}, \mathrm{FWHM} \approx 10 \mathrm{~nm}\right.$, Schott $)$ and solar-blind photomultipliers (Hamamatsu, R759). These components were assembled in water-tight aluminium cylinders for outdoor operation. The cylinders were equipped with cells for drying agents to ensure proper operation of optical and electronic components. The instruments of this campaign represented various versions of commercially available setups by Metcon $\mathrm{GmbH}$. High voltages of the $j\left(\mathrm{O}^{1} \mathrm{D}\right)$-FR were checked before and after the campaign. The final outputs were analogue voltages in a $0-10 \mathrm{~V}$ range that could be recorded continuously. 


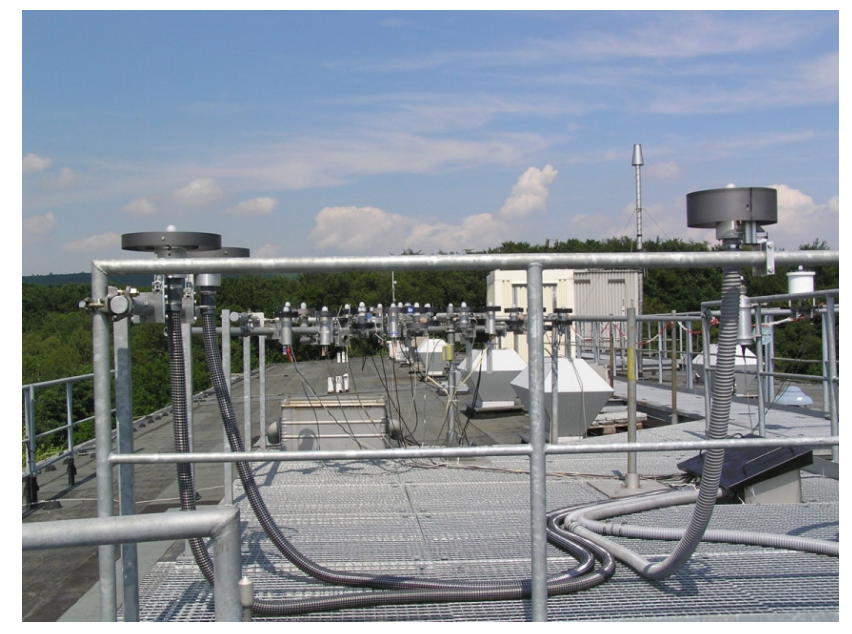

Fig. 3. Photograph taken at the roof platform at Forschungszentrum Jülich on 1 June 2005 during the measurement campaign.

$j\left(\mathrm{NO}_{2}\right)$-FR were available in the form of $2 \pi$ sr instruments and $4 \pi \mathrm{sr}$ instruments with two opposite $2 \pi$ sr receiver optics. After half of the campaign the latter instruments were rotated by $180^{\circ}$ to obtain calibrations for both sides.

Accuracy estimates for filter radiometers are difficult because they depend on the accuracy of the reference method used for calibration. Moreover, instrument specific long-term drifts or spectral response properties may lead to time and condition dependent uncertainties (see Sect. 3.2 for more details).

\subsection{Campaign location and conditions}

The intercomparison was conducted on a roof platform at Forschungszentrum Jülich $(50.91 \mathrm{~N}, 6.41 \mathrm{E}, 110 \mathrm{~m}$ a.s.l.) during the period 1 June-12 June 2005. The campaign period was selected to cover the maximum range of solar zenith angles possible for this latitude, i.e. SZA $\geq 27^{\circ}$. The platform provided virtually full view of the upper hemisphere $(\approx 97 \%)$. Figure 3 shows a photograph of the platform taken during the campaign. The roof underneath the platform was covered with black roofing fabric and the building was mainly surrounded by trees exhibiting low reflectivity in the UV. This limited local up-welling actinic flux. Mutual influence of instruments mounted at the same level at distances $>25 \mathrm{~cm}$ was estimated $<0.3 \%$. Underneath the platform a laboratory was arranged housing DM-SR, FR power supplies, data loggers and control computers.

In Fig. 4 measurements of global shortwave radiation $(\lambda \leq 3 \mu \mathrm{m})$ during the campaign period are plotted. These data were obtained with a pyranometer (CM7, Kipp-Zonen) and correspond to the solar radiant energy flux density incident at a horizontal surface (solar irradiance). The data represent a fundamental meteorological quantity used here to characterise the measurement conditions. Solar irradiances
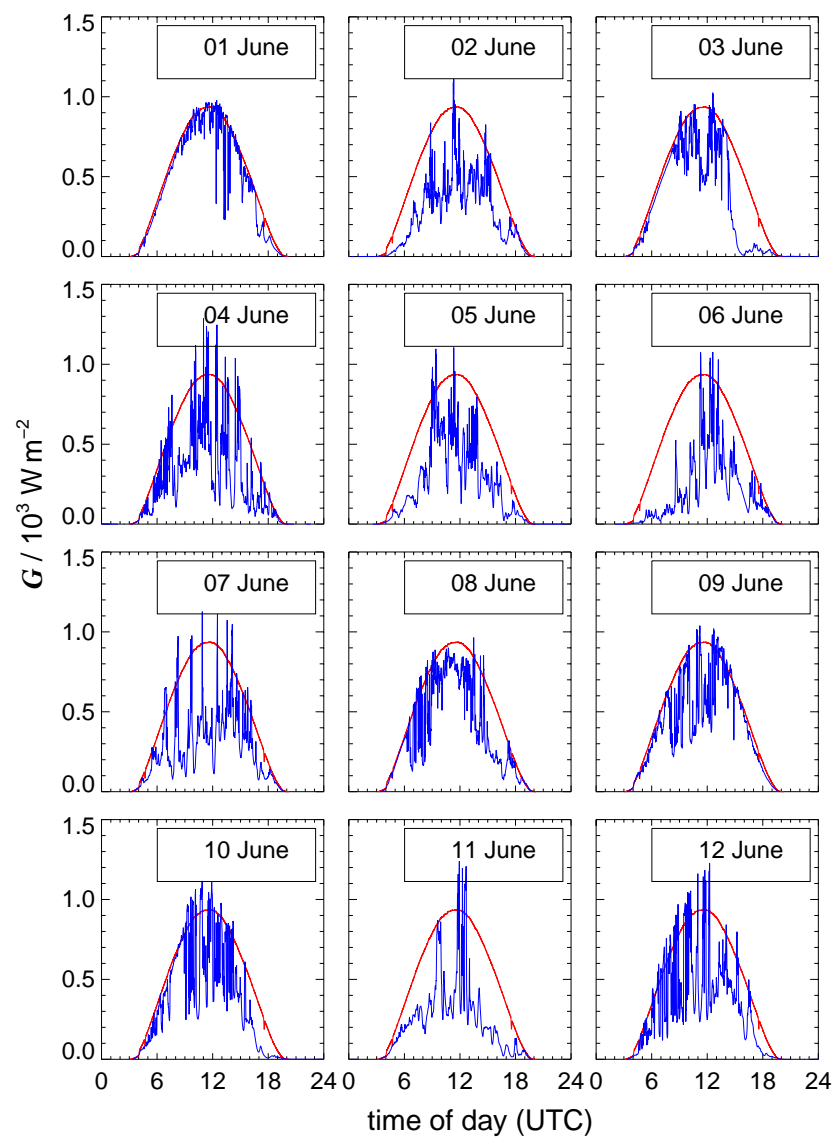

Fig. 4. 1-min averages of global shortwave radiation (solar irradiance) during the 2005 measurement campaign (blue). The strong variability indicated mostly cloudy conditions. The red line shows clear sky data from 12 June 2006 for comparison.

showed strong variability caused by clouds. Unfortunately, clear-sky conditions were rare during the measurement period. For comparison clear-sky data observed on 12 June 2006 are plotted in Fig. 4. This comparison shows that occasionally solar irradiances were significantly greater than under clear-sky indicating broken-cloud conditions where reflections on clouds led to enhanced irradiances. On the other hand, clouds effectively reduced solar irradiances when the sun's disc was blocked. Overall the campaign period apparently offered the desired dynamic range of natural insolation conditions albeit superposed by rapid changes.

\subsection{Timing and data handling}

Recording of analogue FR data was made with a common data logger (Disys, PCI-13) provided by FZJ except for the two instruments by ULI for which 1 min averages were recorded separately. For all the other FR data, recording was made with a time resolution of $1 \mathrm{~s}$ and $5 \mathrm{~s}$ averages were saved. The clocks of the computers controlling the FZJ data logger and FZJ spectroradiometers were networksynchronised. After initial synchronisation the DWD-SR 
Table 2. Ratios $j / j_{\text {ref }}$ of photolysis frequencies calculated from simulated TUV 4.3 clear sky solar actinic flux spectra. The reference spectrum was simulated for 1 June 11:20 UTC (noon) with a wavelength resolution of $0.1 \mathrm{~nm}$. Photolysis frequencies were calculated using Eq. (10). $j_{\text {ref }}$ was obtained using $\Delta \lambda=0.1 \mathrm{~nm}$. The $j$ were calculated after imposing different spectral resolutions (FWHM) to the reference spectrum and using experimental $\Delta \lambda$ and two methods of numerical integration. Method 1: re-interpolation of $F_{\lambda}$ spectra to a $0.1 \mathrm{~nm}$ wavelength grid. Method 2: $\sigma \times \phi$ averages over FWHM wavelength ranges (see Sect. 3.1.1).

\begin{tabular}{|c|c|c|c|c|}
\hline \multirow{5}{*}{$\begin{array}{l}\text { process } \\
j\left(\mathrm{NO}_{2}\right) \\
j(\mathrm{HCHO})_{\mathrm{m}} \\
j(\mathrm{HCHO})_{\mathrm{r}} \\
j\left(\mathrm{O}^{1} \mathrm{D}\right)\end{array}$} & \multicolumn{2}{|c|}{$\begin{array}{l}\text { DM-SR: FWHM }=1.0 \mathrm{~nm}, \Delta \lambda=1.0 \mathrm{~nm} \\
\text { method } 1 \quad \text { method } 2\end{array}$} & \multicolumn{2}{|c|}{$\begin{array}{l}\text { SM-SR: FWHM=2.0 } \mathrm{nm}, \Delta \lambda=0.83 \mathrm{~nm} \\
\text { method } 1 \quad \operatorname{method~} 2\end{array}$} \\
\hline & 0.999 & 0.999 & 0.999 & 0.994 \\
\hline & 0.982 & 0.984 & 0.971 & 0.963 \\
\hline & 0.981 & 0.984 & 0.969 & 0.956 \\
\hline & 1.010 & 1.008 & 1.025 & 1.015 \\
\hline
\end{tabular}

computer clock remained within $2 \mathrm{~s}$ compared to FZJ. The drifting time-shifts of two further computer clocks (IUP, ULI) and that of the ULI data logger were recorded on a daily basis and linearly interpolated after the campaign. After correction, synchronisation of clocks was estimated to be within $2 \mathrm{~s}$.

\section{Results and discussion}

\subsection{Spectroradiometers}

3.1.1 Calculation of photolysis frequencies and influence of FWHM

For the analysis of all spectroradiometer data, common absorption cross sections and quantum yields from the literature were used assuming a temperature of $298 \mathrm{~K}$. For O $\mathrm{O}_{3}$ absorption cross sections by Malicet et al. (1995) and $\mathrm{O}\left({ }^{1} \mathrm{D}\right)$ quantum yields by Matsumi et al. (2002) were selected. For $\mathrm{NO}_{2}$ absorption cross sections by Merienne et al. (1995) and quantum yields by Troe (2000) were used and for HCHO absorption cross sections by Meller and Moortgat (2000) and quantum yields recommended by Atkinson et al. (2004).

Technically photolysis frequencies were obtained by summation of the products $F_{\lambda} \sigma \phi$ at the measurement wavelengths $\lambda_{i}$ and multiplication by the step-size $\Delta \lambda$ :

$j(\mathrm{~A} \rightarrow \mathrm{B}) \approx \sum_{i} F_{\lambda}\left(\lambda_{i}\right) \sigma_{\mathrm{A}}\left(\lambda_{i}\right) \phi_{\mathrm{B}}\left(\lambda_{i}\right) \Delta \lambda$

Absorption cross sections were available with higher spectral resolutions compared to the $F_{\lambda}$ measurements and quantum yields. Two methods were tested to deal with the different resolutions. In method 1 data were forced to a common wavelength grid with $\Delta \lambda=0.1 \mathrm{~nm}$ by averaging $\sigma$ and linearly interpolating $\phi$ and $F_{\lambda}$ (Hofzumahaus et al., 1999). Alternatively (method 2), the experimental $\Delta \lambda$ of $1.0 \mathrm{~nm}$ (DM-SR) and $0.83 \mathrm{~nm}$ (SM-SR) were used and the molecular data were averaged over the FWHM of the instruments.

To find out if the FWHM or the method of calculation had an influence on photolysis frequencies, an actinic flux reference spectrum with $\Delta \lambda$ and full width resolution of $0.1 \mathrm{~nm}$ was calculated using a radiation transfer model (TUV 4.3 by S. Madronich, http://cprm.acd.ucar.edu/Models/TUV/). A clear sky spectrum for 1 June 2005 was calculated for noon time conditions assuming TUV standard aerosol load and a NASA-TOMS based ozone column of 340 DU. Because no absolute comparison with measured spectra was intended the choice of these parameters was considered secondary. To reproduce the spectral resolutions of the instruments, Gaussian curves with the experimental FWHM were used to degrade the simulated high resolution spectrum. Photolysis frequencies were calculated for the reference spectrum and the spectra with the reduced resolutions using the two methods outlined above. The ratios $j / j_{\text {ref }}$ of the photolysis frequencies are listed in Table 2. The results show that for $j\left(\mathrm{NO}_{2}\right)$ no significant deviations $(>1 \%)$ were found. For the other photolysis frequencies both methods provided similar results within $\pm 2 \%$ of the reference calculation at a FWHM of $1 \mathrm{~nm}$. At a FWHM of $2 \mathrm{~nm}$ method 1 gave results within $\pm 3 \%$ of the reference while method 2 produced slightly improved results for $j\left(\mathrm{O}^{1} \mathrm{D}\right)(+2 \%)$ and slightly poorer results for $j(\mathrm{HCHO})$ $(-4 \%)$. Overall differences between method 1 and method 2 were minor and no recommendation was made. Considering the FWHM of DM-SR and SM-SR in this work, differences on the order $2 \%$ for $j(\mathrm{HCHO})$ were expected due to spectra resolution differences. The results obtained here with method 1 were consistent with previous conclusions by Hofzumahaus et al. (1999) who used a similar approach.

\subsubsection{Campaign overview}

Figures 5 and 6 show an overview of $j\left(\mathrm{NO}_{2}\right)$ and $j\left(\mathrm{O}^{1} \mathrm{D}\right)$ data obtained during the period 1 June-12 June 2005. FZJSR2 data were selected for this overview because this instrument also provided information on the presence and contribution of direct sun. In accordance with the solar irradiances shown in Fig. 4, the photolysis frequencies exhibited strong variability and rapidly changing contributions of direct sun. However, compared with the solar irradiances the variations caused by clouds were less pronounced in particular for $j\left(\mathrm{O}^{1} \mathrm{D}\right)$. The values of $j\left(\mathrm{NO}_{2}\right)$ and $j\left(\mathrm{O}^{1} \mathrm{D}\right)$ represent 

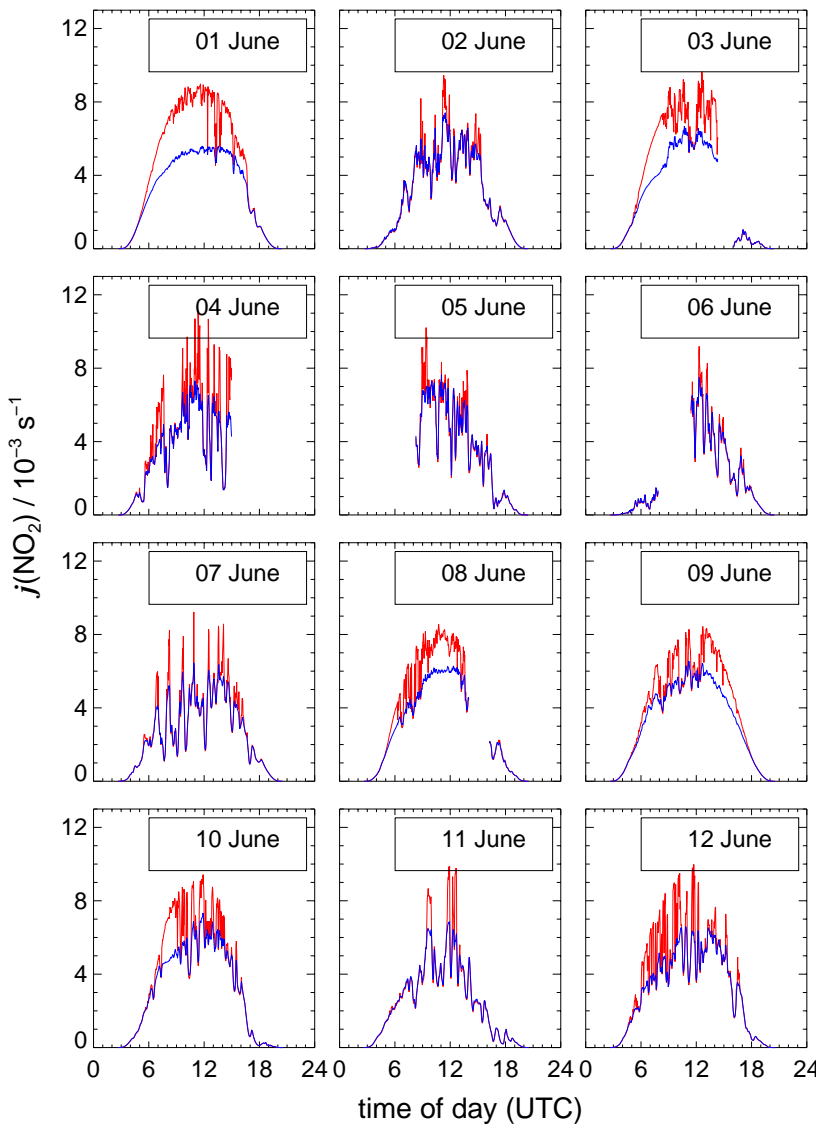

Fig. 5. $j\left(\mathrm{NO}_{2}\right)$ during the 2005 measurement period. Data were obtained with FZJ-SR2. Red: total $j\left(\mathrm{NO}_{2}\right)$, blue: $j\left(\mathrm{NO}_{2}\right)$ from diffuse sky radiation. The differences corresponded to the contributions from direct sun.

in good approximation the UV-A and UV-B range, respectively. Thus, on a relative scale stronger Rayleigh scattering and absorption by stratospheric ozone expectedly led to narrower diurnal shapes and lower contributions of direct sun for $j\left(\mathrm{O}^{1} \mathrm{D}\right)$ than for $j\left(\mathrm{NO}_{2}\right) . j(\mathrm{HCHO})_{\mathrm{r}}$ and $j(\mathrm{HCHO})_{\mathrm{m}}$ are not shown here because they exhibit relative diurnal variations between those of Figs. 5 and 6.

\subsubsection{FZJ-SR2}

Figure 7 compares FZJ-SR2 data with those of the reference instrument. Correlation plots (left) and ratios as a function of SZA (right) are plotted. The synchronised data for these plots were obtained by linear interpolation of the reference instrument data to the FZJ-SR2 time axis. In this procedure the measurement times for both instruments were defined by the centres of the integrals in Eq. (2). Note that for scanning spectroradiometers wavelength is proportional to time within a spectrum. The FZJ-SR2 time axis was selected for interpolation because the reference data had a higher time resolution. The resulting scatter was mainly caused by the combined influences of clouds and the differences in the scanning
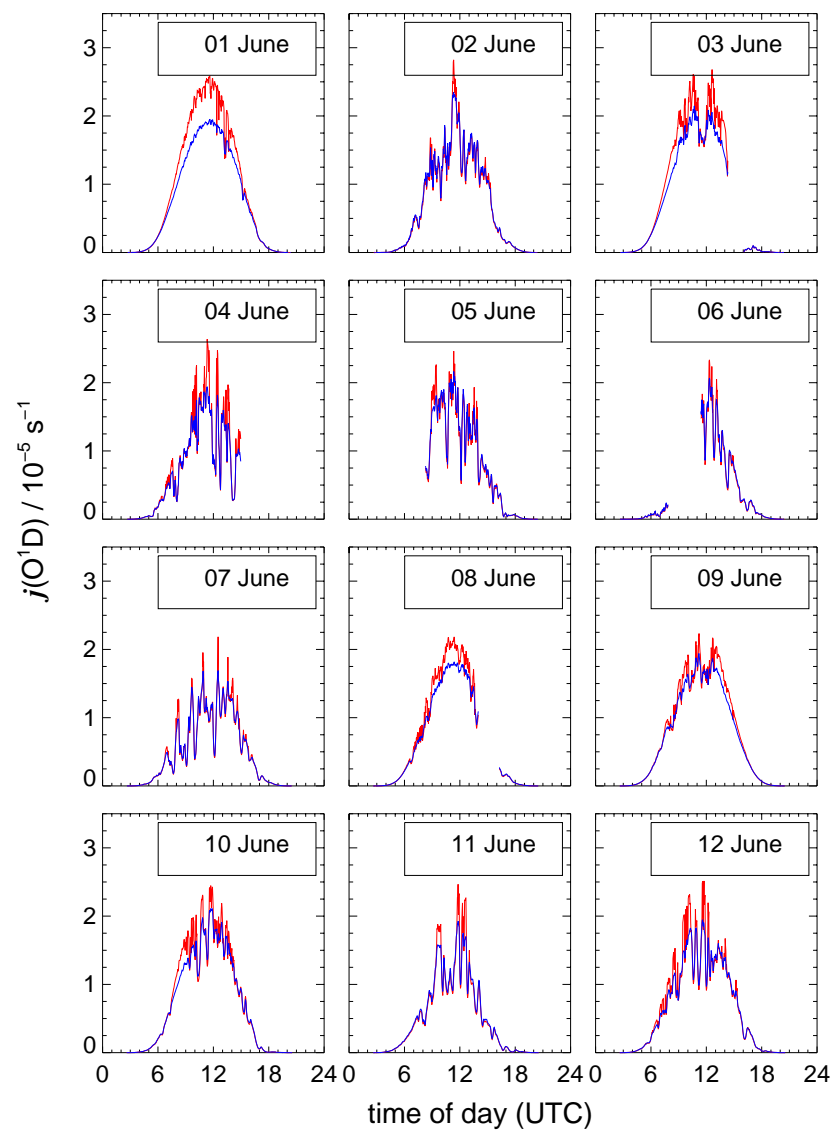

Fig. 6. $j\left(\mathrm{O}^{1} \mathrm{D}\right)$ during the 2005 measurement period. Data were obtained with FZJ-SR2. Red: total $j\left(\mathrm{O}^{1} \mathrm{D}\right)$, blue: $j\left(\mathrm{O}^{1} \mathrm{D}\right)$ from diffuse sky radiation. The differences corresponded to the contributions from direct sun.

times of the instruments, i.e. by the imperfect synchronisation of the scanning schemes rather than instrument precisions. This scatter appears random, but dependent on conditions (SZA, cloud movement, etc.). In previous comparisons of the instruments FZJ-SR1 and FZJ-SR2 with synchronised scanning schemes (unpublished results) lower scatter was observed independent of external conditions confirming this interpretation. Upon averaging the data over longer time periods (e.g. $30 \mathrm{~min}$ ) the scatter strongly reduced in the correlation plots of Fig. 7 while the slopes remained virtually unchanged. However, such averaging made the assignment of SZA less precise and was therefore not implemented.

Linear regressions of the data in the correlation plots resulted in slopes close to unity within $2 \%$ for all photolysis frequencies. In Table 3 the corresponding results were listed. Because scatter was dominated by synchronisation effects measurement precisions were not considered in the regressions. Exchanging $x$ and $y$ gave slopes within $0.5 \%$ of the inverse slopes listed in Table 3. Thus, neglecting instrument errors in the regressions did not seem to produce any systematic differences. 
Table 3. Spectroradiometer instrument results overview. Linear regressions (slopes and intercepts) and mean ratios (instrument/reference, reference=FZJ-SR1). For the calculation of mean ratios data were selected where photolysis frequencies were greater than $5 \%$ of maximum values for $j\left(\mathrm{NO}_{2}\right)$ and $j(\mathrm{HCHO})$, and greater than $10 \%$ of maximum values for $j\left(\mathrm{O}^{1} \mathrm{D}\right)$. The errors of the mean ratios are $1 \sigma$ standard deviations. $N=$ number of data points during the period 1-12 June 2005. Numbers in brackets are exponents to base 10 .

\begin{tabular}{|c|c|c|c|c|c|c|c|c|c|}
\hline instrument & $N$ & slope & $\begin{array}{l}j\left(\mathrm{NO}_{2}\right) \\
\text { intercept } / \mathrm{s}^{-1}\end{array}$ & slope & $\begin{array}{l}\mathrm{HCHO})_{\mathrm{m}} \\
\text { intercept } / \mathrm{s}^{-1}\end{array}$ & slope & $\begin{array}{l}(\mathrm{HCHO})_{\mathrm{r}} \\
\text { intercept } / \mathrm{s}^{-1}\end{array}$ & slope & $\begin{array}{l}j\left(\mathrm{O}^{1} \mathrm{D}\right) \\
\text { intercept } / \mathrm{s}^{-1}\end{array}$ \\
\hline FZJ-SR2 ${ }^{\mathrm{a}}$ & 5281 & 0.992 & $-9.0(-6)$ & 0.991 & $-6.1(-8)$ & 0.999 & $-4.7(-8)$ & 1.016 & $-3.2(-8)$ \\
\hline IUP-SR ${ }^{\mathrm{a}}$ & 1693 & 1.023 & $-8.1(-5)$ & 1.041 & $-2.1(-7)$ & 1.049 & $-1.5(-7)$ & 1.075 & $-9.6(-8)$ \\
\hline ULI-SR $^{b}$ & 5960 & 0.971 & $1.8(-5)$ & 0.953 & $7.1(-8)$ & 0.919 & $6.7(-8)$ & 0.963 & $4.5(-7)$ \\
\hline DWD-SR ${ }^{c}$ & 5975 & 0.998 & $1.5(-5)$ & 0.969 & $-1.9(-9)$ & 0.968 & $-1.6(-8)$ & 1.008 & $-2.8(-8)$ \\
\hline \multirow[t]{2}{*}{ FZJ-SR $3^{c}$} & 6731 & 1.004 & $2.1(-5)$ & 0.959 & $2.8(-8)$ & 0.944 & $3.4(-9)$ & 0.978 & $2.0(-8)$ \\
\hline & $N^{\mathrm{d}}$ & \multicolumn{2}{|r|}{ ratio } & \multicolumn{2}{|r|}{ ratio } & \multicolumn{2}{|r|}{ ratio } & \multicolumn{2}{|r|}{ ratio } \\
\hline FZJ-SR2 ${ }^{a}$ & $2913-4106$ & \multicolumn{2}{|r|}{$0.988 \pm 0.035$} & \multicolumn{2}{|c|}{$0.984 \pm 0.035$} & \multicolumn{2}{|c|}{$0.991 \pm 0.036$} & \multicolumn{2}{|r|}{$1.009 \pm 0.038$} \\
\hline IUP-SR $^{\mathrm{a}}$ & 911-1316 & \multicolumn{2}{|r|}{$0.986 \pm 0.063$} & \multicolumn{2}{|c|}{$1.016 \pm 0.058$} & \multicolumn{2}{|c|}{$1.026 \pm 0.059$} & \multicolumn{2}{|r|}{$1.050 \pm 0.061$} \\
\hline ULI-SR ${ }^{b}$ & $3448-4759$ & \multicolumn{2}{|r|}{$0.977 \pm 0.023$} & \multicolumn{2}{|c|}{$0.958 \pm 0.024$} & \multicolumn{2}{|c|}{$0.927 \pm 0.024$} & \multicolumn{2}{|r|}{$1.028 \pm 0.067$} \\
\hline DWD-SR ${ }^{c}$ & $3404-4974$ & \multicolumn{2}{|r|}{$1.008 \pm 0.014$} & \multicolumn{2}{|c|}{$0.973 \pm 0.011$} & \multicolumn{2}{|c|}{$0.969 \pm 0.011$} & \multicolumn{2}{|r|}{$1.008 \pm 0.020$} \\
\hline FZJ-SR $^{c}$ & $3708-5400$ & \multicolumn{2}{|r|}{$1.014 \pm 0.013$} & \multicolumn{2}{|c|}{$0.963 \pm 0.009$} & \multicolumn{2}{|c|}{$0.945 \pm 0.009$} & \multicolumn{2}{|r|}{$0.985 \pm 0.023$} \\
\hline
\end{tabular}

${ }^{\text {a }}$ Reference instrument data interpolated to measurement times

${ }^{\mathrm{b}}$ Instrument data interpolated to reference measurement times

c Averaged data over reference instrument scanning intervals

d Minimum $N$ corresponds to $j\left(\mathrm{O}^{1} \mathrm{D}\right)$, maximum $N$ corresponds to $j\left(\mathrm{NO}_{2}\right)$

The plots on the right hand side of Fig. 7 indicated that the ratios of the photolysis frequencies were independent of SZA. In contrast to the correlation plots this representation equally weights all data independent of the photolysis frequency values. Any systematic deviation towards large SZA would be apparent in these plots. In Table 3 mean ratios and standard deviations are listed for the different photolysis frequencies as an alternative measure for the agreement of the instruments. For these calculations data were selected where photolysis frequencies are greater than $5 \%$ of the maximum values for $j\left(\mathrm{NO}_{2}\right)$ and $j(\mathrm{HCHO})$, and greater than $10 \%$ of maximum values for $j\left(\mathrm{O}^{1} \mathrm{D}\right)$. These limits were chosen because they seemed applicable for all instruments discussed in the following. In Fig. 7 the corresponding data points are color-coded. The mean ratios were in agreement with the slopes from the linear regressions within $1 \%$. The standard deviations of the mean ratios mainly reflect the magnitude of the scatter produced by the synchronisation effects. Overall the agreement of FZJ-SR2 and FZJ-SR1 was within the estimated uncertainties regarding the optical receiver properties $(\approx 2 \%)$.

\subsubsection{IUP-SR}

Figure 8 shows a comparison of IUP-SR and reference data in the same representations as Fig. 7. Synchronisation was made by interpolation of the reference instrument data to the IUP-SR measurement times. Caused by the increased scanning times of IUP-SR $(6 \mathrm{~min})$ the resulting scatter is strongly increased. Linear regressions yielded slopes close to unity with deviations between $2 \%$ for $j\left(\mathrm{NO}_{2}\right)$ and $8 \%$ for $j\left(\mathrm{O}^{1} \mathrm{D}\right)$ (Table 3). The mean ratios of the photolysis frequencies in Table 3 reflect corresponding agreements in reasonable accordance with the regression slopes within error limits. However, the fact that there is a $4 \%$ difference between the regression slope and the mean ratio for $j\left(\mathrm{NO}_{2}\right)$ indicates a slight non-linearity probably caused by the imperfections of the teflon receiver of IUP-SR. Moreover, because the same irradiance standard was used for calibration of IUP-SR and FZJSR1, also the systematic deviations from unity were most likely caused by these imperfections.

The plots of the ratios of photolysis frequencies in Fig. 8 indicate slight dependencies on SZA with minima close to $60^{\circ}$. Qualitatively this behaviour is explained by the properties of the teflon receiver of IUP-SR. At SZA $\approx 60^{\circ}$ the applied correction factor and $Z_{\mathrm{p}}$ compensated each other, i.e. $Z_{\mathrm{p}} / Z_{\mathrm{H}} \approx 1$. Thus direct sun was treated correctly at this SZA while at smaller SZA the correction overcompensated the imperfections of the receiver for direct sun. Occasionally this led to greater values at smaller SZA. Under overcast conditions the correction factor $1 / Z_{\mathrm{H}}$ of 1.52 based on the assumption of an isotropic radiance distribution may be too great by about $6 \%$ if empirical distributions of sky radiance under overcast conditions are taken into account (Grant and Heisler, 1997). Overall, given the uncertainties of the corrections accounting for the deficiencies of the optical receiver the agreement was satisfactory. 

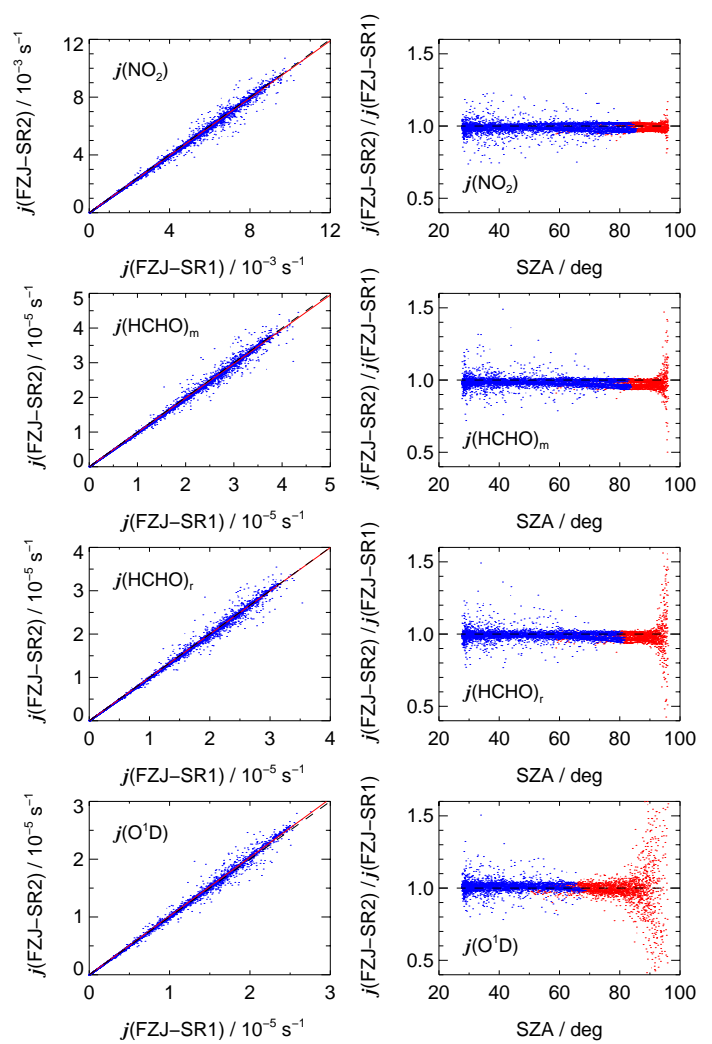

Fig. 7. Left: Correlation plots of photolysis frequencies from FZJSR1 and FZJ-SR2 during the period 1-12 June $2005(N=5281)$. Data of FZJ-SR1 were interpolated to the measurement times of FZJ-SR2. Full lines show linear regressions (Table 3). Dashed black lines indicate the 1:1 relationships. Right: Ratios of photolysis frequencies as a function of solar zenith angles. Red data points indicate values below $5 \%$ of maximum values for $j\left(\mathrm{NO}_{2}\right)$ and $j(\mathrm{HCHO})$, and below $10 \%$ of maximum values for $j\left(\mathrm{O}^{1} \mathrm{D}\right)$.

\subsubsection{ULI-SR}

The comparison of ULI-SR with FZJ-SR1 is shown in Fig. 9. The scatter is small because the ULI-SR data were higher resolved ( $1 \mathrm{~min}$ averages) and were linearly interpolated to the measurement times of the reference instrument. In Table 3 the results of the data analysis are summarised. For $j\left(\mathrm{NO}_{2}\right)$ agreement of ULI-SR with the reference was within $3 \%$. Because calibration was made with a different irradiance standard this result is well within the accuracy estimates of both instruments. For the HCHO photolysis frequencies the agreement was slightly poorer with deviations of about $-5 \%$ and $-8 \%$ for $j(\mathrm{HCHO})_{\mathrm{m}}$ and $j(\mathrm{HCHO})_{\mathrm{r}}$, respectively. These differences were independent of SZA and partly $(\approx 2 \%)$ explainable by the greater FWHM of ULISR (see Sect. 3.1.1). The remaining differences mainly for $j(\mathrm{HCHO})_{\mathrm{r}}$ were explained by the limited accuracy of the sensitivity of the instrument in the UV where both the sensitivity of the photodiode arrays and the irradiance of the standard
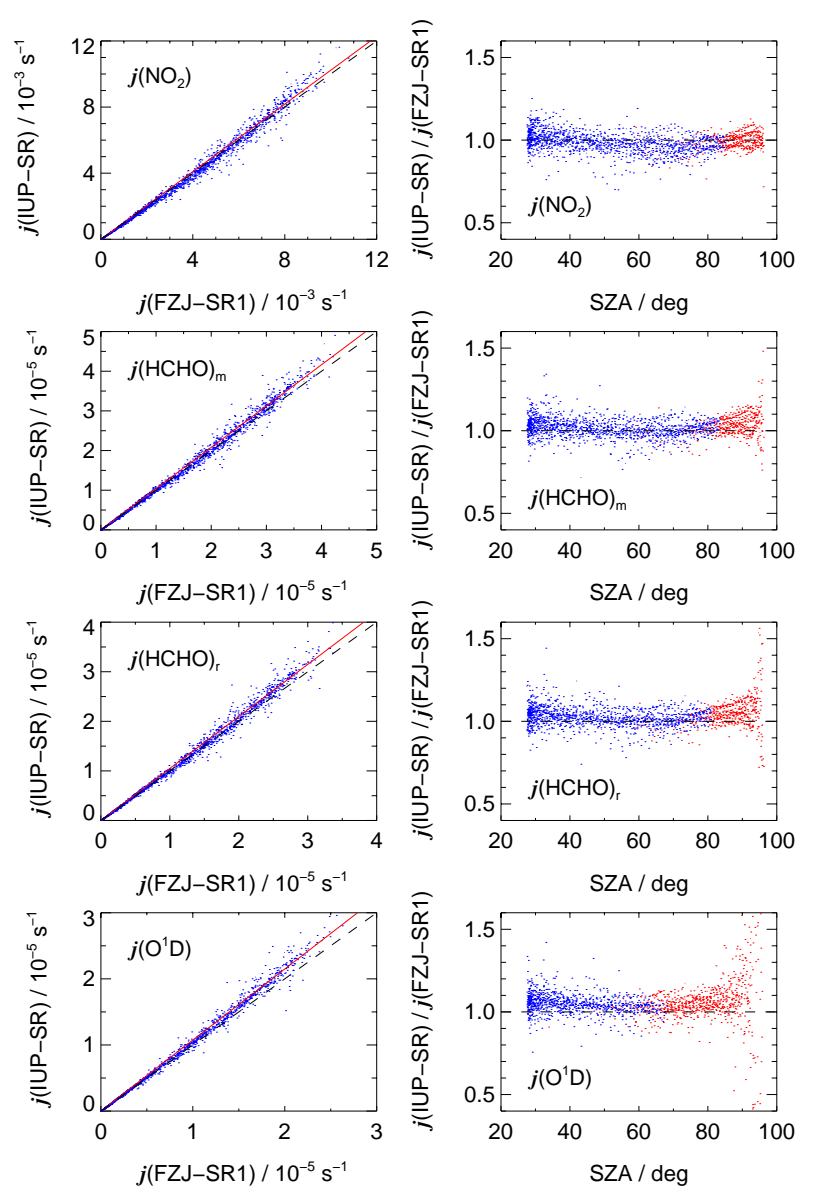

Fig. 8. Left: Correlation plots of photolysis frequencies from FZJSR1 and IUP-SR during the period 2-12 June 2005 ( $N=1693)$. Data of FZJ-SR1 were interpolated to the measurement times of IUP-SR. See Fig. 7 for more details.

lamps strongly decreased. These problems were accounted for by the greater error estimate for ULI-SR in the UV-B range $(9 \%)$ which covers the remaining about $6 \%$ difference.

For $j\left(\mathrm{O}^{1} \mathrm{D}\right)$ there were significant deviations of about $15 \%$ at $\mathrm{SZA} \approx 60^{\circ}$ and $30 \%$ at $\mathrm{SZA} \approx 70^{\circ}$ which further increased towards larger SZA. Similar positive deviations were recognised for the other photolysis frequencies albeit at SZA exceeding $90^{\circ}$ which was considered irrelevant. The reason for these deviations probably was insufficient background and/or stray-light subtraction under the atmospheric measurement conditions. Background was determined in a range 285$290 \mathrm{~nm}$ where no atmospheric radiation is expected. If straylight and/or additional background (cross-talk) increased in the range between $290 \mathrm{~nm}$ and the actual atmospheric cutoff wavelength this led to an overestimation of radiation in this range. At larger SZA the $j\left(\mathrm{O}^{1} \mathrm{D}\right)$ response to these overestimations was extremely sensitive. However, the deviations were hardly visible in the correlation plots in Fig. 9 because they affected times of the day where $j\left(\mathrm{O}^{1} \mathrm{D}\right)$ was small. Deviations exceeding $20 \%$ were only observed at $j\left(\mathrm{O}^{1} \mathrm{D}\right)$ below 

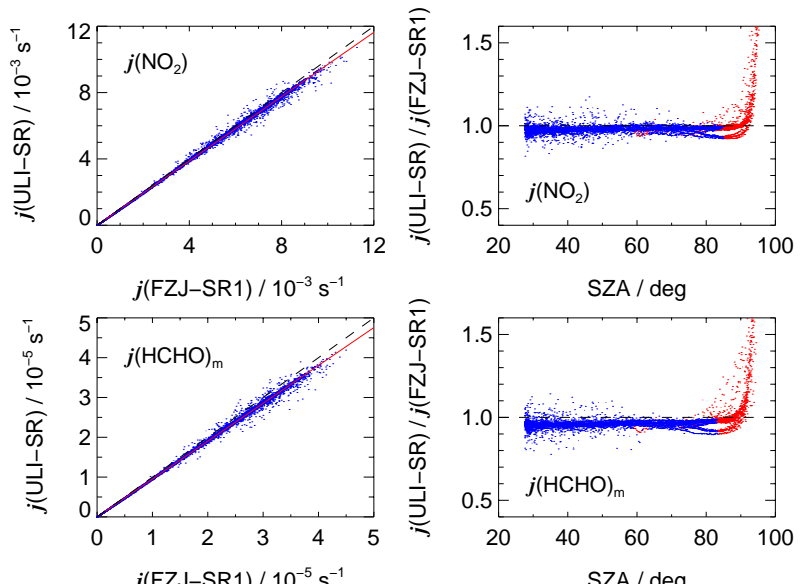

$j(\mathrm{FZJ}-\mathrm{SR} 1) / 10^{-5} \mathrm{~s}^{-1}$
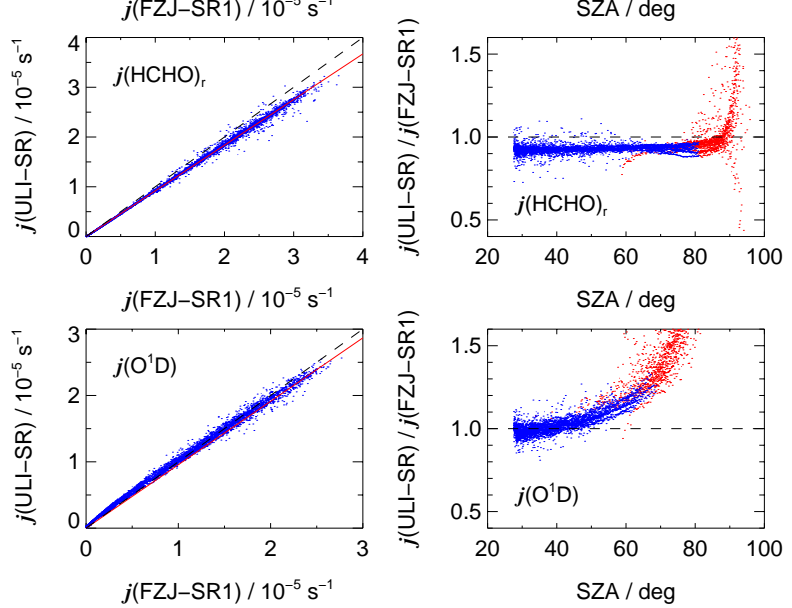

Fig. 9. Left: Correlation plots of photolysis frequencies from FZJSR1 and ULI-SR during the period 1-12 June 2005 ( $N=5960)$. Data of ULI-SR were interpolated to the measurement times of FZJ-SR1. See Fig. 7 for more details.

about $3 \times 10^{-6} \mathrm{~s}^{-1}$ corresponding to about $10 \%$ of the maximum values. Photochemically the impact of these deviations is probably minor.

\subsubsection{DWD-SR}

Figure 10 shows a comparison of DWD-SR and reference instrument data. Synchronisation was made by averaging the DWD-SR data (12 s time resolution) over the respective scanning intervals of the reference instrument. For $j\left(\mathrm{NO}_{2}\right)$ averaging windows of $45 \mathrm{~s}$ were used corresponding to a wavelength range of about $335-410 \mathrm{~nm}$ covering the major fraction of the $\mathrm{NO}_{2}$ photolysis spectral range. For the other photolysis frequencies $25 \mathrm{~s}$ averaging windows were used. As a result of the averaging the scatter decreased further in comparison to the other SR discussed so far. In Table 3 the results of the data analysis were summarised. Regarding $j\left(\mathrm{NO}_{2}\right)$ the result was again excellent with an agreement within $1 \%$ although a third irradiance standard was used for calibration by DWD. The smaller standard deviation of the ratios reflects the higher time resolution of the measurements
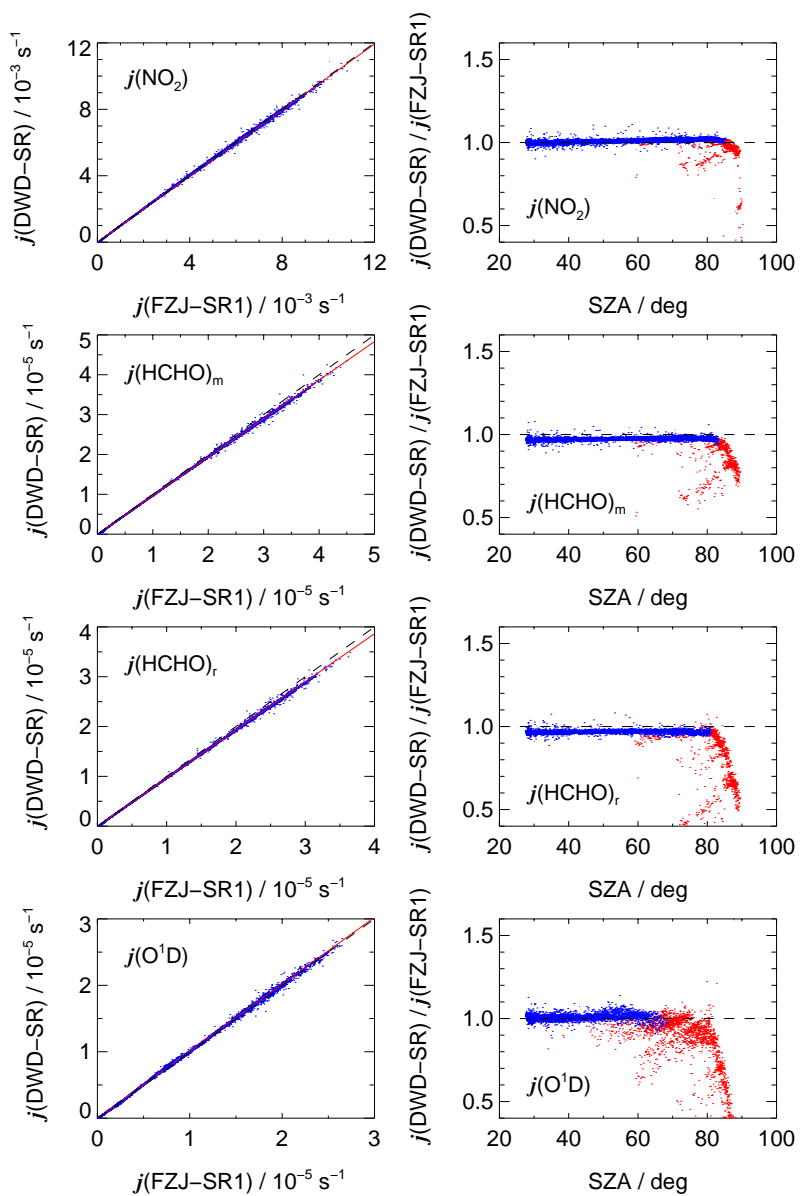

Fig. 10. Left: Correlation plots of photolysis frequencies from FZJSR1 and DWD-SR during the period 1-12 June 2005 ( $N=5975)$. Data of DWD-SR were averaged over the scanning periods of FZJSR1. See Fig. 7 for more details.

further diminishing the cloud effects. Corresponding agreement was found for the other photolysis frequencies with a maximum negative $3-4 \%$ deviation for $j(\mathrm{HCHO})_{\mathrm{r}}$. As explained above this was partly attributed to the lower spectral resolution.

The plots of the ratios as a function of SZA reveal systematic negative deviations towards large SZA mainly for $j\left(\mathrm{O}^{1} \mathrm{D}\right)$. The sporadic deviations at smaller SZA also correspond to low values of photolysis frequencies as indicated by the colors in Fig. 10. The behaviour is opposite to that of ULI-SR and is explained by the different method of background subtraction. A minimum gradient was defined to locate the onset wavelength of atmospheric radiation (Sect. 2.2). This led to an underestimation of spectral actinic flux at lower wavelengths. Nevertheless the approach was justified because apart from the direction, the deviations were smaller compared to the overestimations resulting from constant background subtraction. Deviations exceeding $20 \%$ were only observed at $j\left(\mathrm{O}^{1} \mathrm{D}\right)$ below about $1 \times 10^{-6} \mathrm{~s}^{-1}$ cor- 
responding to about $3 \%$ of maximum values.

It should be noted that the selected minimum gradient was based on the current intercomparison, i.e. the data shown in Fig. 10 were the result of an iterative improvement. This method of background determination is therefore dependent on at least one comparison with a reference instrument to allow this optimisation. On the other hand, the magnitude of the gradient in a wide range only affected $j\left(\mathrm{O}^{1} \mathrm{D}\right)$ at large SZA and hardly influenced the regression results in Table 3.

\subsubsection{FZJ-SR3}

Figure 11 depicts the FZJ-SR3 and the reference instrument data. Synchronisation was made by averaging FZJ-SR3 data with $\approx 8 \mathrm{~s}$ time resolution over the scanning periods of the reference instrument using the same averaging windows as for DWD-SR. The method of background subtraction was similar to that used for DWD-SR but the minimum gradient applied in the data analysis was smaller because the raw signals of the instrument were lower. Nevertheless, with the selected gradient $j\left(\mathrm{O}^{1} \mathrm{D}\right)$ measurements were feasible up to $\mathrm{SZA} \approx 80^{\circ}$.

The overall performance of FZJ-SR3 was comparable with DWD-SR. For $j\left(\mathrm{NO}_{2}\right)$, agreement within $1 \%$ was obtained. Slightly larger deviations of the regression slopes and mean ratios of $-4 \%$ and $-6 \%$ were obtained for $j(\mathrm{HCHO})_{\mathrm{m}}$ and $j(\mathrm{HCHO})_{\mathrm{r}}$, respectively. Although the differences were within the estimated accuracy for the spectral sensitivity measurements under laboratory conditions, the results hint towards a general problem regarding the calibration of the SM-SR because all SM-SR exhibited similar deviations for the $j(\mathrm{HCHO})$. Because $j(\mathrm{HCHO})_{\mathrm{r}}$ was affected more strongly than $j(\mathrm{HCHO})_{\mathrm{m}}$ and $j\left(\mathrm{NO}_{2}\right)$ was unaffected, differences seemed to increase with decreasing wavelength. For $j\left(\mathrm{O}^{1} \mathrm{D}\right)$ this trend may have been compensated or even overcompensated by the background subtraction problems. A review of the calibration procedure and further tests could clarify the cause of these systematic effects. This may also help to improve the performance for $j\left(\mathrm{O}^{1} \mathrm{D}\right)$ measurements at large SZA.

\subsection{Filter radiometers}

\subsection{1 $j\left(\mathrm{NO}_{2}\right)-\mathrm{FR}$}

The $j\left(\mathrm{NO}_{2}\right)$-FR measurements provided continuous, highly time resolved $(5 \mathrm{~s})$ analogue voltage data. Background voltages were determined during the night at $\mathrm{SZA} \geq 98^{\circ}$ and then averaged and subtracted. Except for ULI-FR1 (1 min averages) where interpolations were used, synchronisations with the reference $j\left(\mathrm{NO}_{2}\right)$ data were made by averaging over the SR scanning periods using $45 \mathrm{~s}$ windows. Calibration factors were obtained by linear regressions which were forced through the origins. These factors are listed in Table 4. In Fig. 12 the corresponding photolysis frequencies are plotted
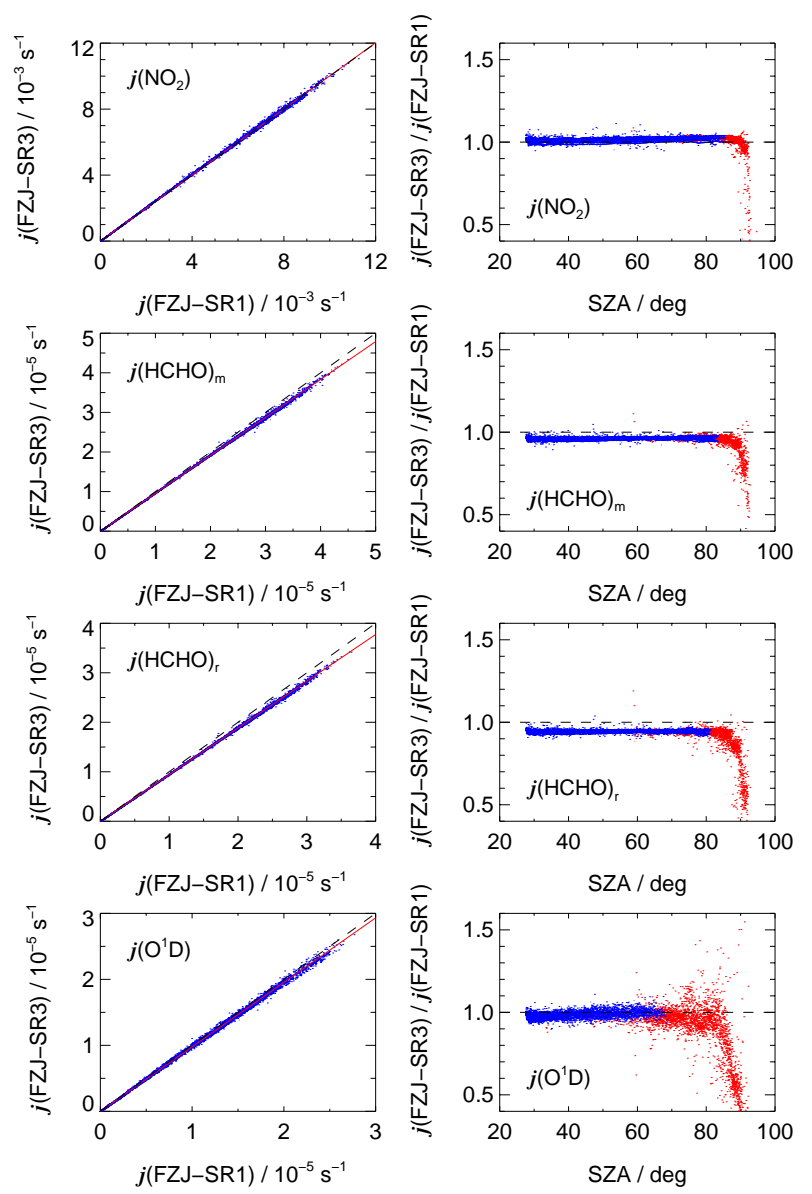

Fig. 11. Left: Correlation plots of photolysis frequencies from FZJSR1 and FZJ-SR3 during the period 1-12 June $2005(N=6731)$. Data of FZJ-SR3 were averaged over the scanning periods of FZJSR1. See Fig. 7 for more details.

against the reference data for the second campaign period 712 June. All instruments show very good linearity which is also reflected in the plots of the ratios as a function of SZA in Fig. 13. For the first campaign period where the opposite sides of the $4 \pi$ sr instruments were operative the figures look very similar. The data are therefore not plotted separately. Calibration factors for this period, mean ratios and standard deviations of the ratios can also be found in Table 4. For the calculation of all ratios data were considered when $j\left(\mathrm{NO}_{2}\right)$ was greater than $5 \%$ of maximum values which is consistent with the analysis for the SR in Table 3.

A single calibration factor was sufficient to convert the background corrected output voltages to $j\left(\mathrm{NO}_{2}\right)$. Except for ICL-FR a slight $\approx 5 \%$ increase of the ratios with SZA was observed. This behaviour is explained by a non-ideal matching of the instrument spectral sensitivities with the product of $\sigma \phi$ for $\mathrm{NO}_{2}$ photolysis. The spectral sensitivities of FZJFR1 and FZJ-FR2 were determined in the laboratory and the magnitude and direction of the deviations were reproducible 
Table 4. $j\left(\mathrm{NO}_{2}\right)$-FR results overview. Calibration factors from linear regressions of this work, previous calibration factors, and mean ratios of $j\left(\mathrm{NO}_{2}\right)$ (instrument/reference) after application of the calibration factors. Error limits of mean ratios correspond to $1 \sigma$ standard deviations. For the ratios data were considered where $j\left(\mathrm{NO}_{2}\right)$ was greater than $5 \%$ of maximum values.

\begin{tabular}{|c|c|c|c|c|c|}
\hline instrument & \# & calibration period & $\begin{array}{l}\text { calibration factor / } \\
\text { this work (2005) }\end{array}$ & $\begin{array}{l}10^{-3} \mathrm{~s}^{-1} \mathrm{~V}^{-1} \\
\text { previous (year) }\end{array}$ & ratio \\
\hline \multicolumn{6}{|c|}{$4 \pi \mathrm{sr}$ instruments } \\
\hline \multirow[t]{2}{*}{ ICL-FR } & 012 & 1-6 June & 1.91 & $1.76^{\mathrm{a}}$ & $1.003 \pm 0.030$ \\
\hline & 010 & 7-12 June & 1.87 & $1.97^{\mathrm{a}}$ & $1.000 \pm 0.033$ \\
\hline \multirow[t]{2}{*}{ PSI-FR } & 401 & 1-6 June & 1.02 & $1.04^{\mathrm{b}}$ & $1.009 \pm 0.020$ \\
\hline & 402 & 7-12 June & 1.08 & $1.13^{\mathrm{b}}$ & $1.008 \pm 0.021$ \\
\hline \multirow[t]{2}{*}{ DWD-FR1 } & 511 & 1-6 June & 1.37 & $1.31(2001)$ & $1.014 \pm 0.027$ \\
\hline & 501 & 7-12 June & 1.01 & $1.03(2004)$ & $1.011 \pm 0.022$ \\
\hline \multirow[t]{2}{*}{ FZJ-FR1 } & 614 & 1-6 June & 1.55 & $1.54(2002)$ & $1.009 \pm 0.025$ \\
\hline & 615 & 7-12 June & 1.34 & $1.32(2002)$ & $1.010 \pm 0.024$ \\
\hline \multirow{2}{*}{ FZJ-FR2 } & 616 & 1-6 June & 1.34 & $1.26(2002)$ & $1.009 \pm 0.027$ \\
\hline & 617 & 7-12 June & 1.47 & $1.43(2002)$ & $1.010 \pm 0.022$ \\
\hline \multicolumn{6}{|c|}{$2 \pi$ sr instruments } \\
\hline \multirow[t]{3}{*}{ MET-FR } & 739 & 1-12 June & 2.27 & $2.32(2001)$ & $1.009 \pm 0.022$ \\
\hline & & 1-6 June & 2.28 & & $1.010 \pm 0.023$ \\
\hline & & 7-12 June & 2.26 & & $1.009 \pm 0.021$ \\
\hline \multirow[t]{3}{*}{ UCR-FR1 } & 741 & 1-12 June & 1.68 & 1.69 (2004) & $1.005 \pm 0.019$ \\
\hline & & 1-6 June & 1.69 & & $1.007 \pm 0.019$ \\
\hline & & 7-12 June & 1.67 & & $1.005 \pm 0.020$ \\
\hline \multirow[t]{3}{*}{ ULI-FR1 } & $\mathrm{n} / \mathrm{a}$ & 1-12 June & 4.67 & 4.59 (2002) & $1.011 \pm 0.030$ \\
\hline & & 1-6 June & 4.70 & & $1.011 \pm 0.026$ \\
\hline & & 7-12 June & 4.63 & & $1.010 \pm 0.032$ \\
\hline MPIC-FR1 & 408 & 9-12 June & 5.79 & $5.64(2004)$ & $1.011 \pm 0.024$ \\
\hline MPIC-FR2 & 686 & 9-12 June & 5.07 & $5.12(2004)$ & $1.013 \pm 0.025$ \\
\hline
\end{tabular}

a $10-15$ year old calibration based on a comparison with a reference FR calibrated against a chemical actinometer.

$\mathrm{b}$ The date of the calibration is unknown. Previously applied factors were greater by a factor of two to account for the use of a voltage divider.

with the reference instrument spectra of this work. The reason that ICL-FR showed the opposite behaviour remains unclear. It may contain a different filter combination. The small deviations towards larger SZA could be compensated using polynomial calibration fits rather than single factors. However, the possible improvements were considered minor.

Three $2 \pi$ sr instruments (ULI-FR1, UCR-FR1, MET-FR) were operated during the whole campaign. If the results of the first period (1-6 June) and the second period (7-12 June) are compared, a drift of about $1 \%$ towards smaller calibration factors was consistently found for all three instruments. This drift was attributed to the reference instrument but considered insignificant within error limits.

A comparison with previous calibration factors showed good stability for most instruments. Except for ICL-FR, PSIFR and ULI-FR the previous calibration factors were based on similar comparisons with FZJ-SR1 or FZJ-SR2 indicat- ing stable calibration factors over several years. The previous ICL-FR calibration was obtained from a comparison with a reference FR calibrated with a chemical actinometer. Although these calibrations date back 10-15 years, the factors are still within a 5-8\% range of the 2005 values confirming the long-term stability of the instrument. Nevertheless, regular checks of calibration factors are recommended. If no spectroradiometer reference is available a calibrated $j\left(\mathrm{NO}_{2}\right)$ FR can be used as a secondary reference. Consistency checks can also be made with $4 \pi$ sr instruments by repeatedly rotating the instrument under stable atmospheric conditions or by comparison with radiation transfer model results under clear sky conditions. However, model calculations should not be considered as an absolute reference because of uncertainties regarding aerosol loads. Examples of the influence of air pollution on $j\left(\mathrm{NO}_{2}\right)$ can be found elsewhere (e.g. Thielmann et al., 2002; Hodzic et al., 2007). 


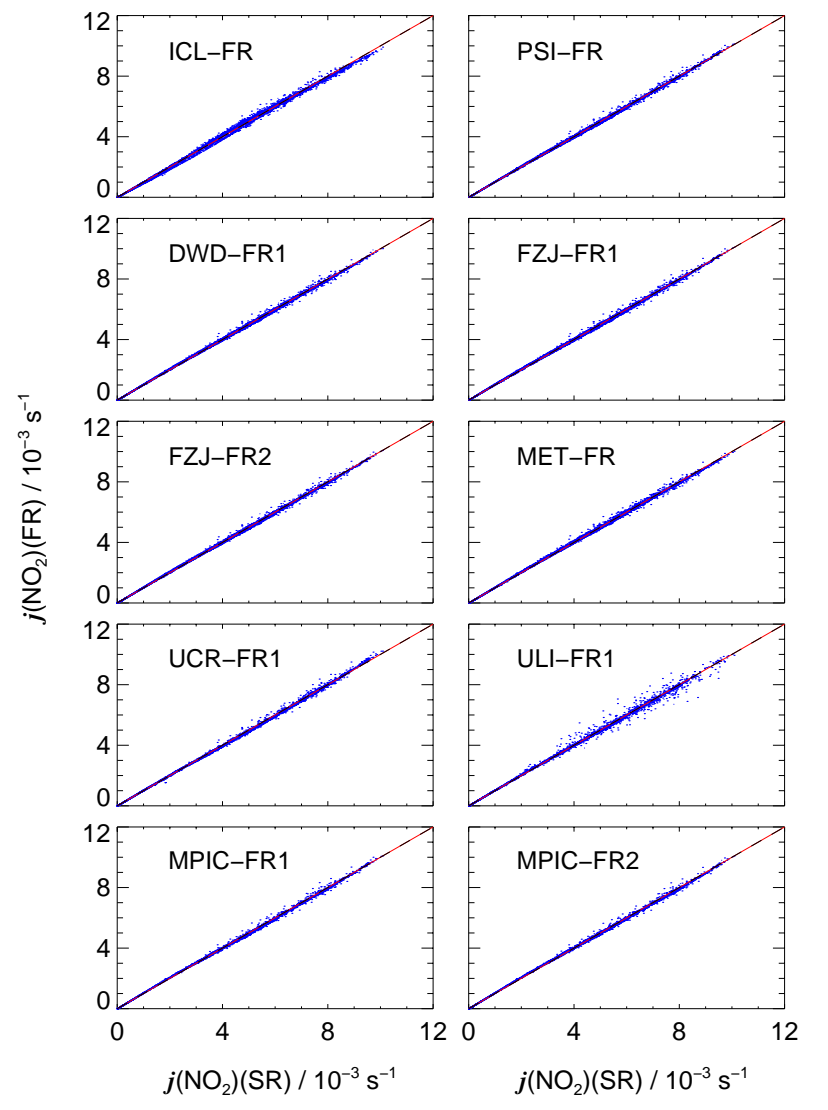

Fig. 12. Correlation plots of $j\left(\mathrm{NO}_{2}\right)$ photolysis frequencies from FZJ-SR 1 and $j\left(\mathrm{NO}_{2}\right)$-FR during the period 7-12 June 2005. Full lines correspond to 1:1 relationships after application of the calibration factors from Table 4.

\subsection{2 $j\left(\mathrm{O}^{1} \mathrm{D}\right)-\mathrm{FR}$}

The $j\left(\mathrm{O}^{1} \mathrm{D}\right)$-FR measurements also provide continuous, highly time resolved analogue voltage data. Background voltages were determined during the night at $\mathrm{SZA} \geq 98^{\circ}$ and then averaged and subtracted. With the exception of ULIFR2 (1 min averages) synchronisations with the reference $j\left(\mathrm{O}^{1} \mathrm{D}\right)$ data were made by averaging over the reference scanning periods using $25 \mathrm{~s}$ windows.

$j\left(\mathrm{O}^{1} \mathrm{D}\right)$-FR data analysis is more complex because there is normally no linear relationship between $j\left(\mathrm{O}^{1} \mathrm{D}\right)$ and output voltages. The reason for this non-linearity is the strong variability of the solar spectrum in the UV-B range as a function of ozone column and SZA combined with nonideal spectral responses of the instruments. To compensate for this, output signals were multiplied by instrumentspecific correction functions considering ozone column and SZA prior to conversion to $j\left(\mathrm{O}^{1} \mathrm{D}\right)$ with an adjustable calibration factor. These calculations were made by the participants using their usual routines after common data sets containing ozone columns, SZA and averaged instrument
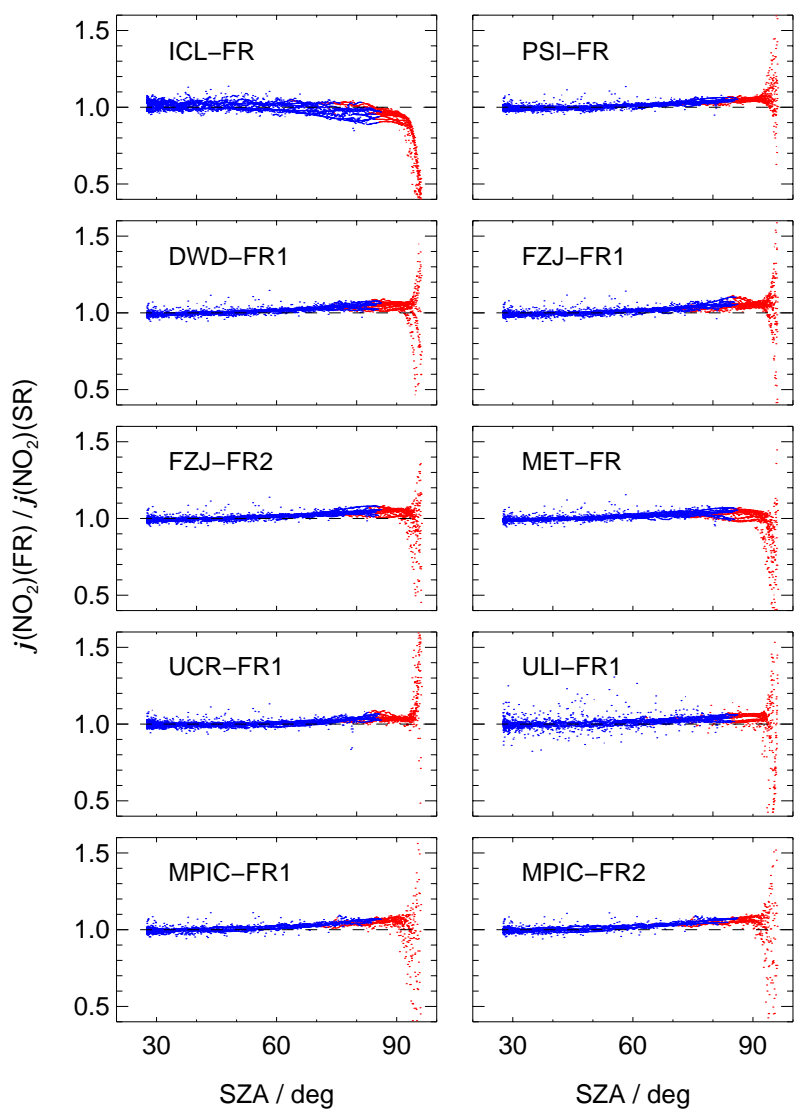

Fig. 13. Ratios of $j\left(\mathrm{NO}_{2}\right)$ photolysis frequencies as a function of solar zenith angle during the period 7-12 June 2005. Red data points indicate values below $5 \%$ of maximum values.

voltages for the $j\left(\mathrm{O}^{1} \mathrm{D}\right)$ measurement times were circulated. Ozone columns were taken from NASA/GSFC TOMS (http: //toms.gsfc.nasa.gov/) where daily data from the Earth-Probe satellite were available in June 2005.

From the $j\left(\mathrm{O}^{1} \mathrm{D}\right)$-FR data provided by the participants and the $j\left(\mathrm{O}^{1} \mathrm{D}\right)$ reference data, linear regressions were performed which resulted in scaling factors to update previous calibration factors. These scaling factors varied in the range 0.981.23 and are listed in Table 5. Correlation plots and plots of the resulting ratios as a function of SZA can be found in Figs. 14 and 15 . Table 5 also lists the mean $j\left(\mathrm{O}^{1} \mathrm{D}\right)$ ratios and the $1 \sigma$ standard deviations. As for the spectroradiometers in these calculations only data were taken into account when $j\left(\mathrm{O}^{1} \mathrm{D}\right)$ was greater than $10 \%$ of maximum values. The respective data points are color-coded in Fig. 15. Scaling factors are reported here instead of calibration factors to avoid confusion with the calibration factors in Table 4 which directly convert output voltages to $j\left(\mathrm{NO}_{2}\right)$. Combinations of calibration factors and correction functions are necessary to obtain $j\left(\mathrm{O}^{1} \mathrm{D}\right)$ but details of the correction functions applied by the participants are complex and will not be discussed in this work. 
Table 5. $j\left(\mathrm{O}^{1} \mathrm{D}\right)-\mathrm{FR}$ results overview. Scaling factors from linear regressions of this work updating old calibration factors and mean ratios of $j\left(\mathrm{O}^{1} \mathrm{D}\right)$ (instrument/reference) after application of the scaling factors. Error limits of mean ratios correspond to $1 \sigma$ standard deviations. For the ratios data were considered where $j\left(\mathrm{O}^{1} \mathrm{D}\right)$ was greater than $10 \%$ of maximum values.

\begin{tabular}{ccccc}
\hline Instrument & $\#$ & calibration period & $\begin{array}{c}\text { scaling factor } \\
\text { this work / old (year) }\end{array}$ & ratio \\
\hline UCR-FR2 & 102 & 1-12 June & $1.230(2003)$ & $0.979 \pm 0.047$ \\
FZJ-FR3 & 110 & 1-12 June & $1.163(2003)$ & $0.993 \pm 0.027$ \\
ULE-FR & 111 & 1-12 June & $0.985(2002)$ & $0.994 \pm 0.026$ \\
FZJ-FR4 & 119 & 1-12 June & $1.169(2003)$ & $1.008 \pm 0.037$ \\
DWD-FR2 & 120 & 1-12 June & $0.994(2004)$ & $1.006 \pm 0.041$ \\
DWD-FR3 & 126 & 1-12 June & $1.015(2004)$ & $0.997 \pm 0.024$ \\
ULI-FR2 & n/a & 1-12 June & $1.225(2002)$ & $1.000 \pm 0.089$ \\
\hline
\end{tabular}

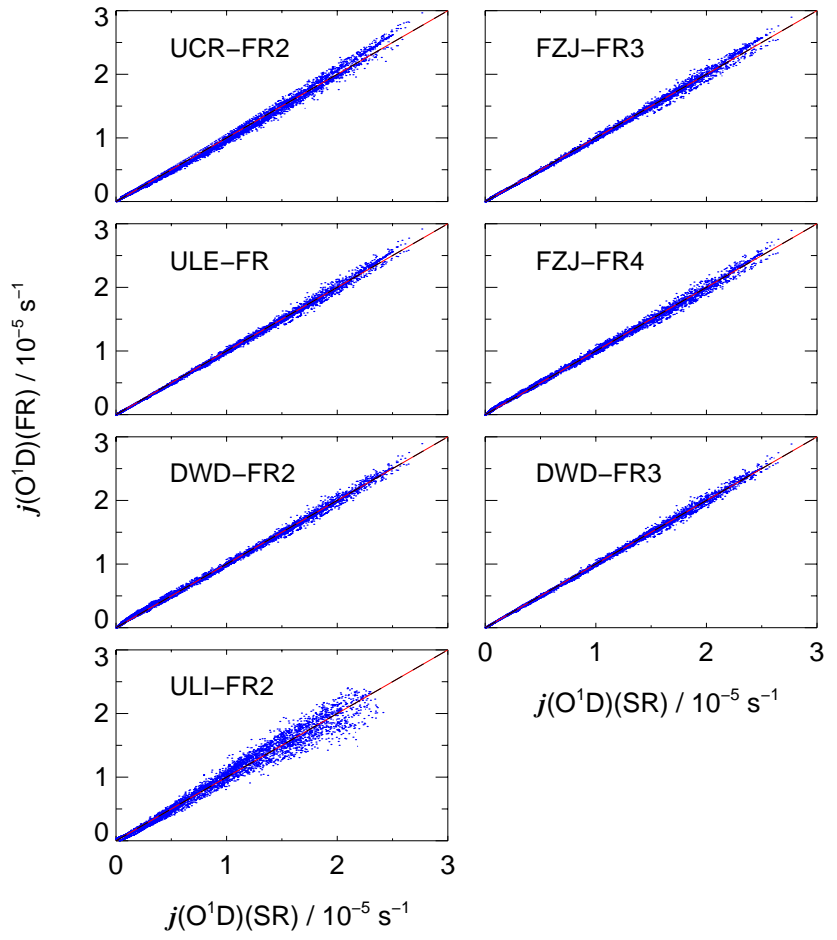

Fig. 14. Correlation plots of $j\left(\mathrm{O}^{1} \mathrm{D}\right)$ photolysis frequencies from FZJ-SR1 and $j\left(\mathrm{O}^{1} \mathrm{D}\right)-\mathrm{FR}$ during the period $1-12$ June 2005 . Full lines correspond to 1:1 relationships after application of the scaling factors from Table 5 .

Compared with the $j\left(\mathrm{NO}_{2}\right)$-FR the performance of the $j\left(\mathrm{O}^{1} \mathrm{D}\right)$-FR is poorer. Scatter towards large SZA is greater and for some instruments significant systematic deviations are evident at SZA greater than $60^{\circ}$. Nevertheless, differences are acceptable at smaller SZA or great $j\left(\mathrm{O}^{1} \mathrm{D}\right)$. Systematic deviations at large SZA are attributed to inadequate correction functions with regard to ozone column and SZA. These functions were derived in the past from the spectral sensitivities of the instruments, simulated actinic flux spectra and the molecular data $\sigma\left(\mathrm{O}_{3}\right)$ and $\phi\left(\mathrm{O}^{1} \mathrm{D}\right)$. The theoret-

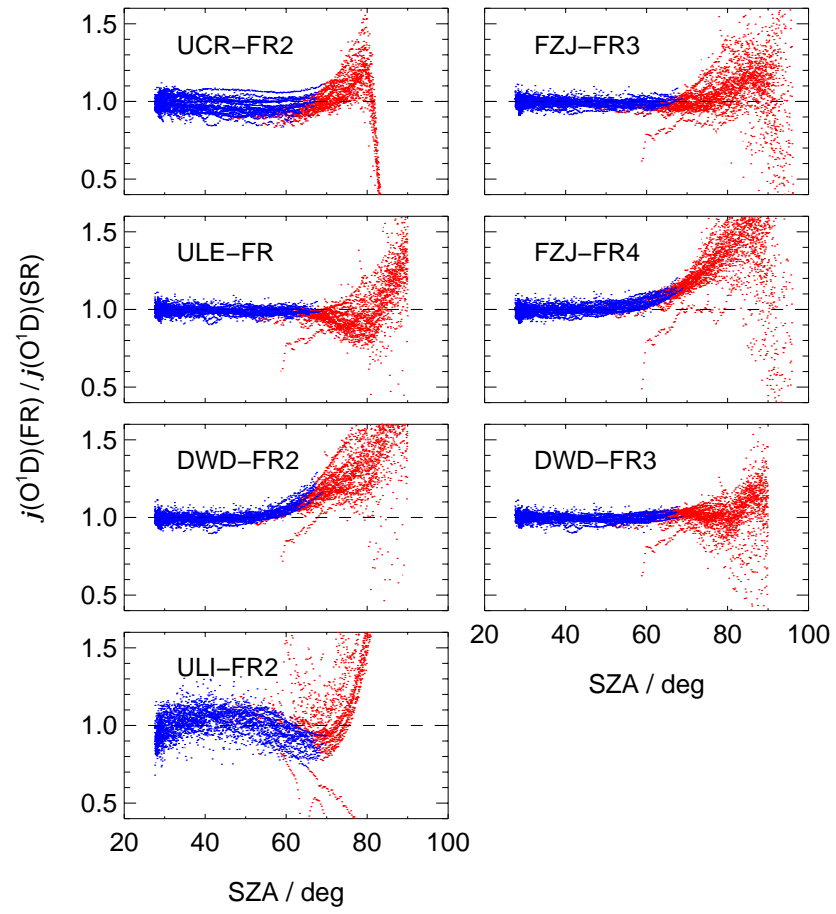

Fig. 15. Ratios of $j\left(\mathrm{O}^{1} \mathrm{D}\right)$ photolysis frequencies as a function of solar zenith angle during the period 1-12 June 2005. Red data points indicate values below $10 \%$ of maximum values.

ical background of this approach was described elsewhere (Bohn et al., 2004). Most participants use parameterisations for the correction functions which were purchased with the instruments. However, regarding $\phi\left(\mathrm{O}^{1} \mathrm{D}\right)$ there were significant changes in the recommendations since 1994 (Matsumi et al., 2002; Hofzumahaus et al., 2004). Consequently, older correction functions may have been outdated and improved corrections could not be calculated because the current spectral sensitivities of the instruments were unknown. Overall based on the intercomparison alone no improvement of the correction functions is feasible. 
The deviations of the scaling factors from unity for some instruments indicate drifts of the calibration factors. This could be caused by an aging of the PMTs used for radiation detection. Calibrations should therefore be made on a regular basis or before and after field campaigns to trace any drifts. Alternatively irradiance standards can be used to monitor drifts on a relative scale between successive calibrations. This method has already been used in a long-term study on the relationship between $j\left(\mathrm{O}^{1} \mathrm{D}\right)$ and $\mathrm{OH}$ radical concentrations (Rohrer and Berresheim, 2006). However, after technical problems, e.g. water penetration or replacement of optical components, calibrations against a reference are essential to obtain new calibrations factors and to check the validity of the correction functions. Irradiance standards can also be used for absolute calibrations of $j\left(\mathrm{O}^{1} \mathrm{D}\right)$-FR if the relative spectral sensitivities are known (Bohn et al., 2004) but this approach was not considered here because the data were not available. Finally, $j\left(\mathrm{O}^{1} \mathrm{D}\right)$-FR data should be corrected for the significant temperature dependence of $j\left(\mathrm{O}^{1} \mathrm{D}\right)$ for which parameterisations were derived (Bohn et al., 2004). For the current work no such correction was necessary.

\section{Conclusions}

The DM-SR used in this work showed good agreement within estimated instrumental uncertainties $(\approx 2 \%$ for $\left.j\left(\mathrm{NO}_{2}\right)\right)$. Somewhat larger discrepancies for one instrument were explained by a suboptimal optical teflon receiver. For future applications this instrument will be equipped with a receiver with improved angular response properties. The major drawback of the DM-SR is the long scanning time with sequential recording of spectra producing measurement uncertainties under variable atmospheric conditions. On the other hand the technique is essential as a reference for accurate and sensitive measurements in the UV-B.

For the diode array based SM-SR agreement with the DMSR reference was good for $j\left(\mathrm{NO}_{2}\right)$ and $j(\mathrm{HCHO})$ with minor $(\leq 8 \%)$ systematic deviations for $j(\mathrm{HCHO})$. The SM-SR suffered from sensitivities decreasing with wavelength in the UV, insufficient stray-light suppression and cross-talk within the detector arrays. Consequently, accuracies in the UV-B were slightly poorer and $j\left(\mathrm{O}^{1} \mathrm{D}\right)$ values obtained at larger SZA were dependent on the method of background determination. For $j\left(\mathrm{O}^{1} \mathrm{D}\right)$ the gradient method searching for the atmospheric cutoff in the spectra provided slightly better results than background determinations in a range below $290 \mathrm{~nm}$. The problem of low UV sensitivities was recently improved with instruments using CCD array detectors rather than diode arrays but the method of background determination remains a critical issue (e.g. Eckstein et al., 2003; Jäkel et al., 2007). It is believed that SM-SR will become a standard for photolysis frequency measurements because of undeniable advantages regarding time resolution, stability and weight. However, comparisons with DM-SR references will remain a useful means to characterise the instruments and to optimise methods of background subtraction. Within the ACCENT project a further intercomparison is planned with different types of CCD array and diode array based SM-SR.

$j\left(\mathrm{NO}_{2}\right)$-FR are reliable instruments for $j\left(\mathrm{NO}_{2}\right)$ measurements with a high degree of linearity and good detection limit allowing measurements until sunset or even beyond. In this work no indication for stronger drifts of calibration factors was found.

$j\left(\mathrm{O}^{1} \mathrm{D}\right)$-FR also provide a useful alternative for spectroradiometer measurements. However, data analysis is rather complex and calibration factors seemed to be subject to considerable drifts illustrating the need for regular calibration checks. In addition stronger deviations towards larger SZA clearly indicate the need for updated characterisations of the instruments and calculation of consistent correction functions. During the ACCENT project a number of the $j\left(\mathrm{O}^{1} \mathrm{D}\right)$ FR addressed in this work were modified. New interference filters were inserted and spectral characterisations were made which led to significant improvements. Upon completion these activities will be described in a separate paper.

The conclusions of the present work are in general agreement with a previous extensive study on photolysis frequency measurements and modelling, namely IPMMI (Bais et al., 2003; Cantrell et al., 2003; Shetter et al., 2003; Hofzumahaus et al., 2004). In these studies also slightly better agreement was obtained for $j\left(\mathrm{NO}_{2}\right)$ than for $j\left(\mathrm{O}^{1} \mathrm{D}\right)$ in particular towards larger SZA. However, besides radiative transfer models also chemical actinometers were employed as absolute references during IPMMI. The choice of molecular data used in this work is based on the IPMMI based recommendations consistent with previous comparisons of spectroradiometers and chemical actinometers (e.g. Müller et al., 1995; Kraus et al., 2000). Thus it is expected that the data of this work are both accurate within about 5-10\% and consistent because the data analyses were based on the same molecular data. However, this may not apply for $j(\mathrm{HCHO})$ where greater uncertainties still exist in particular for the quantum yields of the molecular and radical reaction channels.

Acknowledgements. Financial support of the ACCENT project by the European Commission is gratefully acknowledged. K. C. Clemitshaw and L. J. Clapp gratefully acknowledge the assistance of David L. Ames with the operation of the ICL-FR. A. S. H. Prevot is grateful to Institute for Atmospheric and Climate Science at ETH Zürich for providing the PSI-FR. M. Vrekoussis acknowledges consecutive supporting fellowships by the A. v. Humboldt Foundation and the EU (Marie Curie - Intra European Fellowships). Public provision of total ozone column data by the NASA/GSFC TOMS Ozone Processing Team is gratefully acknowledged.

Edited by: J. W. Bottenheim 


\section{References}

Atkinson, R., Baulch, D. L., Cox, R. A., Crowley, J. N., Hampson, R. F., Hynes, R. G., Jenkin, M. E., Rossi, M. J., and Troe, J.: Evaluated kinetic and photochemical data for atmospheric chemistry: Part 1 - gas phase reactions of $\mathrm{O}_{\mathrm{x}}, \mathrm{HO}_{\mathrm{x}}, \mathrm{NO}_{\mathrm{x}}$ and $\mathrm{SO}_{\mathrm{x}}$ species, Atmos. Chem. Phys., 4, 1461-1738, 2004, http://www.atmos-chem-phys.net/4/1461/2004/.

Bais, A., Madronich, S., Crawford, J., Hall, S., Mayer, B., van Weele, M., Lenoble, J., Calvert, J., Cantrell, C., Shetter, R., Hofzumahaus, A., Koepke, P., Monks, P., Frost, G., McKenzie, R., Krotkov, N., Kylling, A., Swartz, W., Lloyd, S., Pfister, G., Martin, T., Roeth, E.-P., Griffioen, E., Ruggaber, A., Krol, M., Kraus, A., Edwards, G., Mueller, M., Lefer, B., Johnston, P., Schwander, H., Flittner, D., Gardiner, B., Barrick, J., and Schmitt, R.: International Photolysis Frequency Measurement and Model Intercomparison (IPMMI): Spectral actinic solar flux measurements and modeling, J. Geophys. Res, 108, 8543, doi:10.1029/2002JD002891, 2003.

Bohn, B. and Zilken, H.: Model-aided radiometric determination of photolysis frequencies in a sunlit atmosphere simulation chamber, Atmos. Chem. Phys., 5, 191-206, 2005, http://www.atmos-chem-phys.net/5/191/2005/.

Bohn, B., Kraus, A., Müller, M., and Hofzumahaus, A.: Measurement of atmospheric $\mathrm{O}_{3} \rightarrow \mathrm{O}\left({ }^{1} \mathrm{D}\right)$ photolysis frequencies using filterradiometry, J. Geophys. Res., 109, D10S90, doi:10.1029/2003JD004319, 2004.

Cantrell, C., Calvert, J., Bais, A., Shetter, R., Lefer, B., and Edwards, G.: Overview and conclusions of the International Photolysis Frequency Measurement and Modeling Intercomparison (IPMMI) study, J. Geophys. Res., 108, 8542, doi:10.1029/2002JD002962, 2003.

Clemitshaw, K. C.: A review of instrumentation and measurement techniques for ground-based and airborne field studies of gasphase tropospheric chemistry, Crit. Rev. Environ. Sci. Technol., 34, 1-108, 2004.

Eckstein, E., Perner, D., Brühl, C., and Trautmann, T.: A new actinic flux $4 \pi$-spectroradiometer: instrument design and application to clear sky and broken cloud conditions, Atmos. Chem. Phys., 3, 1965-1979, 2003, http://www.atmos-chem-phys.net/3/1965/2003/.

Edwards, G. D. and Monks, P. S.: Performance of a single monochromator diode array spectroradiometer for the determination of actinic flux and atmospheric photolysis frequencies, $\mathrm{J}$. Geophys. Res., 108, 8546, doi:10.1029/2002JD002844, 2003.

Ehhalt, D. H.: Photooxidation of trace gases in the troposphere, Phys. Chem. Chem. Phys., 1, 5401-5408, 1999.

Grant, R. H. and Heisler, G. M.: Obscured overcast sky radiance distributions for ultraviolet and photosynthetically active radiation, J. Appl. Meteorol., 36, 1336-1345, 1997.

Hodzic, A., Madronich, S., Bohn, B., Massie, S., Menut, L., and Wiedinmyer, C.: Wildfire particulate matter in Europe during summer 2003: meso-scale modeling of smoke emissions, transport and radiative effects, Atmos. Chem. Phys., 7, 4043-4064, 2007 ,

http://www.atmos-chem-phys.net/7/4043/2007/.

Hofzumahaus, A.: Measurement of Photolysis Frequencies in the Atmosphere, in: Analytical Techniques for Atmospheric Measurement, edited by: Heard, D. E., chap. 9, 406-500, Blackwell Publishing, 2006.
Hofzumahaus, A., Kraus, A., and Müller, M.: Solar actinic flux spectroradiometry: A technique for measuring photolysis frequencies in the atmosphere, Appl. Opt., 38, 4443-4460, 1999.

Hofzumahaus, A., Kraus, A., Kylling, A., and Zerefos, C. S.: Solar actinic radiation $(280-420 \mathrm{~nm})$ in the cloud-free troposphere between ground and $12 \mathrm{~km}$ altitude: Measurements and model results, J. Geophys. Res., 107, 2002.

Hofzumahaus, A., Lefer, B. L., Monks, P. S., Hall, S. R., Kylling, A., Mayer, B., Shetter, R. E., Junkermann, W., Bais, A., Calvert, J. G., Cantrell, C. A., Madronich, S., Edwards, G. D., Kraus, A., Müller, M., Bohn, B., Schmitt, R., Johnston, P., McKenzie, R., Frost, G. J., Griffioen, E., Krol, M., Martin, T., Pfister, G., Röth, E. P., Ruggaber, A., Swartz, W. H., Lloyd, S. A., and VanWeele, M.: Photolysis frequency of $\mathrm{O}_{3}$ to $\mathrm{O}\left({ }^{1} \mathrm{D}\right)$ : Measurement and modelling during the international photolysis frequency measurement and modelling intercomparision (IPMMI), J. Geophys. Res., 109, D08S90, doi:10.1029/2003JD004333, 2004.

Jäckel, E., Wendisch, M., Kniffka, A., and Trautmann, T.: Airborne system for fast measurements of upwelling and downwelling spectral actinic flux densities, Appl. Opt., 44, 434-444, 2005.

Jäckel, E., Wendisch, M., and Lefer, B.: Parameterization of ozone photolysis frequency in the lower troposhere using data from photodiode array detector spectrometers, J. Atmos. Chem., 54, 67-87, 2006.

Jäkel, E., Wendisch, M., Blumthaler, M., Schmitt, R., and Webb, A. R.: A CCD spectroradiometer for ultraviolet actinic radiation measurements, J. Atmos. Ocean. Tech., 24, 449-462, doi:10.1175/JTECH1979.1, 2007.

Jenkin, M. E. and Clemitshaw, K. C.: Ozone and other secondary photochemical pollutants: chemical processes governing their formation in the planetary boundary layer, Atmos. Environ., 34, 2499-2527, 2000.

Junkermann, W., Platt, U., and Volz-Thomas, A.: A photoelectric detector for the measurement of photolysis frequencies of ozone and other atmospheric molecules, J. Atmos. Chem., 8, 203-227, 1989.

Kanaya, Y., Kajii, Y., and Akimoto, H.: Solar actinic flux and photolysis frequency determinations by radiometers and a radiative transfer model at Rishiri Island: comparisons, cloud effects, and detection of an aerosol plume from Russian forest fires, Atmos. Environ., 37, 2463-2475, 2003.

Kraus, A., Rohrer, F., and Hofzumahaus, A.: Intercomparison of $\mathrm{NO}_{2}$ photolysis frequency measurements by actinic flux spectroradiometry and chemical actinometry during JCOM97, J. Geophys. Res. Lett., 27, 1115-1118, 2000.

Malicet, J., Daumont, D., Charbonnier, J., Parisse, C., Chakir, A., and Brion, J.: Ozone UV Spectroscopy II: Absorption crosssections and temperature dependence, J. Atmos. Chem., 21, 263273, 1995.

Matsumi, Y., Comes, F. J., Hancock, G., Hofzumahaus, A., Hynes, A. J., Kawasaki, M., and Ravishankara, A. R.: Quantum yields for production of $\mathrm{O}\left({ }^{1} \mathrm{D}\right)$ in the ultraviolet photolysis of ozone: Recommendation based on evaluation of laboratory data, J. Geophys. Res., 107(D3), 4024, doi:10.1029/2001JD000510, 2002.

Meller, R. and Moortgat, G. K.: Temperature dependence of the absorption cross sections of formaldehyde between 223 and $323 \mathrm{~K}$ in the wavelength range $225-375 \mathrm{~nm}$, J. Geophys. Res., 105, 7089-7101, 2000. 
Merienne, M. F., Jenouvrier, A., and Coquart, B.: The $\mathrm{NO}_{2}$ absorption spectrum: 1. Absorption cross-sections at ambient temperature in the 300-500 nm region, J. Atmos. Chem., 20, 281-297, 1995.

Monks, P., Rickard, A., Hall, S., and Richards, N.: Attenuation of spectral actinic flux and photolysis frequencies at the surface through homogeneous cloud fields, J. Geophys. Res., 109, D17206, doi:10.1029/2003JD004076, 2004.

Müller, M., Kraus, A., and Hofzumahaus, A.: $\mathrm{O}_{3} \rightarrow \mathrm{O}\left({ }^{1} \mathrm{D}\right)$ photolysis frequencies determined from spectroradiometric measurements of solar actinic UV-radiation: Comparison with chemical actinometer measurements, Geophys. Res. Lett., 22, 679-682, 1995.

Rohrer, F. and Berresheim, H.: Strong correlation between levels of tropospheric hydroxyl radicals and solar ultraviolet radiation, Nature, 442, doi:10.1038/nature04924, 2006.

Shetter, R. E., Cantrell, C. A., Lantz, K. O., Flocke, S. J., Orlando, J. J., Tyndall, G. S., Gilpin, T. M., Fischer, C. A., Madronich, S., Calvert, J. G., and Junkermann, W.: Actinometric and radiometric measurement and modeling of the photolysis rate coefficient of ozone to $\mathrm{O}\left({ }^{1} \mathrm{D}\right)$ during the Mauna Loa Observatory Photochemistry Experiment 2, J. Geophys. Res., 101, 10 631-10 642, 1996.

Shetter, R. E. and Müller, M.: Photolysis frequency measurements using actinic flux spectroradiometry during PEM-Tropics Mission: Instrumentation description and some results, J. Geophys. Res., 104, 5647-5661, 1999.

Shetter, R. E., Junkermann, W., Swartz, W. H., Frost, G. J., Crawford, J. H., Lefer, B. L., Barrick, J. D., Hall, S. R., Hofzumahaus, A., Bais, A., Calvert, J. G., Cantrell, C. A., Madronich, S., Müller, M., Kraus, A., Monks, P. S., Edwards, G. D., McKenzie, R., Johnston, P., Schmitt, R., Griffioen, E., Krol, M., Kylling, A., Dickerson, R. R., Lloyd, S. A., Martin, T., Gardiner, B., Mayer, B., Pfister, G., Röth, E. P., Koepke, P., Ruggaber, A., Schwander, H., and van Weele, M.: Photolysis frequency of $\mathrm{NO}_{2}$ : Measurement and modelling during the international photolysis frequency measurement and modelling intercomparision (IPMMI), J. Geophys. Res., 108, 8544, doi:10.1029/2002JD002932, 2003.
Shetter, R., Cinquini, L., Lefer, B., and Madronich, S.: Comparison of airborne measured and calculated spectral actinic flux and derived photolysis frequencies during the PEM Tropics B mission, J. Geophys. Res., 108, doi:10.1029/2001JD001 320, 2003.

Stark, H., Lerner, B. M., Schmitt, R., Jakoubek, R., Williams, E. J., Ryerson, T. B., Sueper, D. T., Parrish, D. D., and Fehsenfeld, F. C.: Atmospheric in situ measurement of nitrate radical $\left(\mathrm{NO}_{3}\right)$ and other photolysis rates using spectroradiometry and filter radiometry, J. Geophys. Res., 112, D10S04, doi:10.1029/2006JD007578, 2007.

Thiel, S., Ammannato, L., Bais, A., Bandy, B., Blumthaler, M., Bohn, B., Engelsen, O., Gobbi, G. P., Gröbner, J., Jäkel, E., Junkermann, W., Kazadzis, S., Kift, R., Kjeldstad, B., Kouremeti, N., Kylling, A., Mayer, B., Monks, P. S., Reeves, C. E., Schallhart, B., Scheirer, R., Schmidt, S., Schmitt, R., Schreder, J., Silbernagl, R., Topaloglou, C., Thorseth, T. M., Webb, A. R., Wendisch, M., and Werle, P.: Influence of clouds on the spectral actinic flux density in the lower troposphere (INSPECTRO): Overview of the field campaigns, Atmos. Chem. Phys., 8, 1789-1812, 2008, http://www.atmos-chem-phys.net/8/1789/2008/.

Thielmann, A., Prevot, A. S. H., and Staehelin, J.: Sensitivity of ozone production derived from field measurements in the Italian Po basin, J. Geophys. Res., 107, 8194, doi:10.1029/2000JD000119, 2002.

Troe, J.: Are primary quantum yields of $\mathrm{NO}_{2}$ photolysis at $\lambda \leq 398 \mathrm{~nm}$ smaller than unity?, Z. Phys. Chem., 214, 573-581, 2000 .

Volz-Thomas, A., Lerner, A., Pätz, H.-W., Schultz, M., McKenna, D. S., Schmitt, R., Madronich, S., and Röth, E. P.: Airborne measurements of the photolysis frequency of $\mathrm{NO}_{2}$, J. Geophys. Res., 101, 18 613-18 627, 1996.

Ylianttila, L. and Schreder, J.: Temperature effects of PTFE diffusers, Opt. Mater., 27, 1811-1814, 2005. 